\title{
Die Jerusalemer Grabeskirche vor 1009
}

\author{
Achim Arbeiter
}

Am Anfang einer längeren Reihe von Beiträgen, die sich einem epochalen Ereignis und seinen Ursachen, Begleitumständen und Konsequenzen zuwenden: der Zerstörung der Jerusalemer Grabeskirche ${ }^{1}$ im Jahr 1009, fällt den folgenden Darlegungen die Aufgabe zu, das ,Vorher' zu betrachten, also die physische Gestalt jenes immens bedeutsamen constantinischen und frühchristlichen Bauwerks. Es wird vorrangig darum gehen, in einem - soweit möglich - beschreibenden Abriss die von der Forschung erreichte und akzeptierte Vision eines weithin verlorenen Architekturdenkmals (Abb. 3, 14) knapp wiederzugeben. Nur in Ansehung des referierenden Charakters seiner Aussagen traut sich der Verfasser zu, im weiteren eine Reihe von Ergebnissen, Einsichten und Annahmen berufenerer Kollegen aus Vergangenheit und Gegenwart über die Urfassung des Grabeskirchen-Komplexes sehr komprimiert und bei Gelegenheit auch kritisch darzubieten. Die Existenz und die Verfügbarkeit des achtbaren Fundus an Daten und Informationen verdanken sich einer großen Zahl von Forschern und Autoren, wobei man wohl gut daran tut, die verdienstvollen Monographien von Virgilio C. Corbo, Charles Coüasnon, Jürgen Krüger und Martin Biddle ${ }^{2}$ noch speziell hervorzuheben. Unsere Bemühung, die aus alledem abgeleiteten Vorstellungen präsent zu machen, soll hier im Übrigen durch eine Auswahl von der Literatur entnommenen Illustrationen unterstützt werden.

Im Jahr 324 eroberte Kaiser Constantin, der schon das Westreich regierte, durch die siegreiche Schlacht von Chrysopolis den gesamten Osten hinzu. Er wurde damit zum Alleinherrscher, und gleichzeitig gelangte damit auch der ohnehin bereits stark christianisierte Osten unter ein christenfreundliches Regime; das neue Credo stand fortan im ganzen Reich unter dauerhaftem Schutz. Besonders im ,Heiligen Land' des 4. Jhs., einer namentlich von lebendigen jüdischen Gemeinschaften geprägten Region, schickte sich das erstarkende Christentum an, den gerade dort für ihn menschgewordenen Gott zu feiern und monu-

1 Die Ausdruck, Grabeskirche“ ist als solcher ebenso eingebürgert wie die Bezeichnung ,Anastasis', doch muss man sich stets vor Augen halten, dass damit eine vielgliedrige Komplexanlage in ihrer Gesamtheit angesprochen ist.

2 V. C. Corbo, Il Santo Sepolcro di Gerusalemme. Aspetti archeologici dalle origini al periodo crociato I-III, Jerusalem 1981-82; Ch. Coüasnon, The Church of the Holy Sepulchre in Jerusalem, London 1974; J. Krüger, Die Grabeskirche von Jerusalem, Regensburg 2000; M. Biddle, The Tomb of Christ, Stroud 1999. 
mental auszuzeichnen. Die Stadt Jerusalem spielte für dieses Land seit langem die Rolle des Zentrums und wurde nun auch zum Epizentrum einer Monumentalisierung im Zeichen des Christentums. ${ }^{3}$

In der palästinischen Küstenstadt Kaisareia hatte damals ein Mann die Bischofskathedrale inne, der alsbald zum entscheidenden Verkünder der constantinisch-imperialen Reichstheologie wurde: Nun, da der Kaiser nicht mehr vergottet werden konnte, war es Bischof Euseb von Kaisareia ( $† 340)$, der die komplizierte Problematik des künftigen Verhältnisses von Herrscher und Gott in einfache und dem Kaiser gefällige Worte fasste. Dieser Oberhirte, einer der einflussreichsten seiner Zeit, stellte sich völlig in den Dienst der ,Constantinischen Wende‘. Der alles überstrahlende Gedanke besagt, dass das kaiserliche Abbild und Nachahmung des Himmlischen sei. Constantin ist Freund, Diener und Vikar Christi, und seine Herrschaft trägt die Merkmale des himmlischen Vorbildes womit er als ein christlicher Kaiser unversehens zwanglos in das Weltbild der Christen passt, ohne dass seiner faktischen Machtstellung Abbruch geschähe. In jener ersten Hälfte des 4. Jhs. waren alle künftigen Kämpfe zwischen weltlicher und kirchlicher Macht noch kaum zu erahnen; man lebte im Überschwang der erreichten und garantierten Freiheit für die Christen. Mehr noch: Constantin persönlich, bestärkt durch seine Mutter Helena, engagierte sich ab 324 unverzüglich und mit allem Nachdruck im Heiligen Land selbst - vor allem durch die Anregung und Förderung christlicher Architekturprojekte.

Von dem streckenweise als illegal gebrandmarkten christlichen Leben der langen vorconstantinischen Zeitspannen ist im palästinischen Bereich materiell fast nichts bewahrt; erst vor kurzem hat die Forschung immerhin eine aufsehenerregende Kultstätte aus dem 3. Jh. bei Megiddo (Abb. 1) ans Licht gebracht. ${ }^{4}$ Sehr geläufig ist zudem, wenn auch nur als ein literarisches Zeugnis, Eusebs lobpreisende Beschreibung der neuen Bischofskirche von Tyros, ${ }^{5}$ ungefähr zum Jahr 314, also aus einer vorübergehenden Toleranzphase. Aber erst nach der letzten Durststrecke unter dem Ostkaiser Licinius, erst nach dessen Ausschaltung durch Constantin im Jahr 324, kam auch für den Osten die definitive Befreiung, ja kaiserliche Favorisierung der Kirche - eine gänzliche Umkehrung der Verhältnisse. Der Kaiser engagierte sich in der Kirchenarchitektur, namentlich an den allerprominentesten Plätzen Palästinas, die Schauplätze der Heilsgeschichte waren. Es handelte sich mithin um Memorialbauten: Constantins Kirchen entstanden in Mambre an der Abrahamseiche, in Bethlehem an der Geburtsstätte,

3 E. D. Hunt, Constantine and Jerusalem, in: Journal of Ecclesiastical History 48 (1997) 405-427.

4 Y. Tepper - L. Di Segni, A Christian prayer hall of the third century CE at Kefar 'Othnay (Legio), Jerusalem 2006.

5 Hist. eccl. 10,4 = Eusebius von Caesarea, Kirchengeschichte, München 1967, $413 \mathrm{ff}$. 


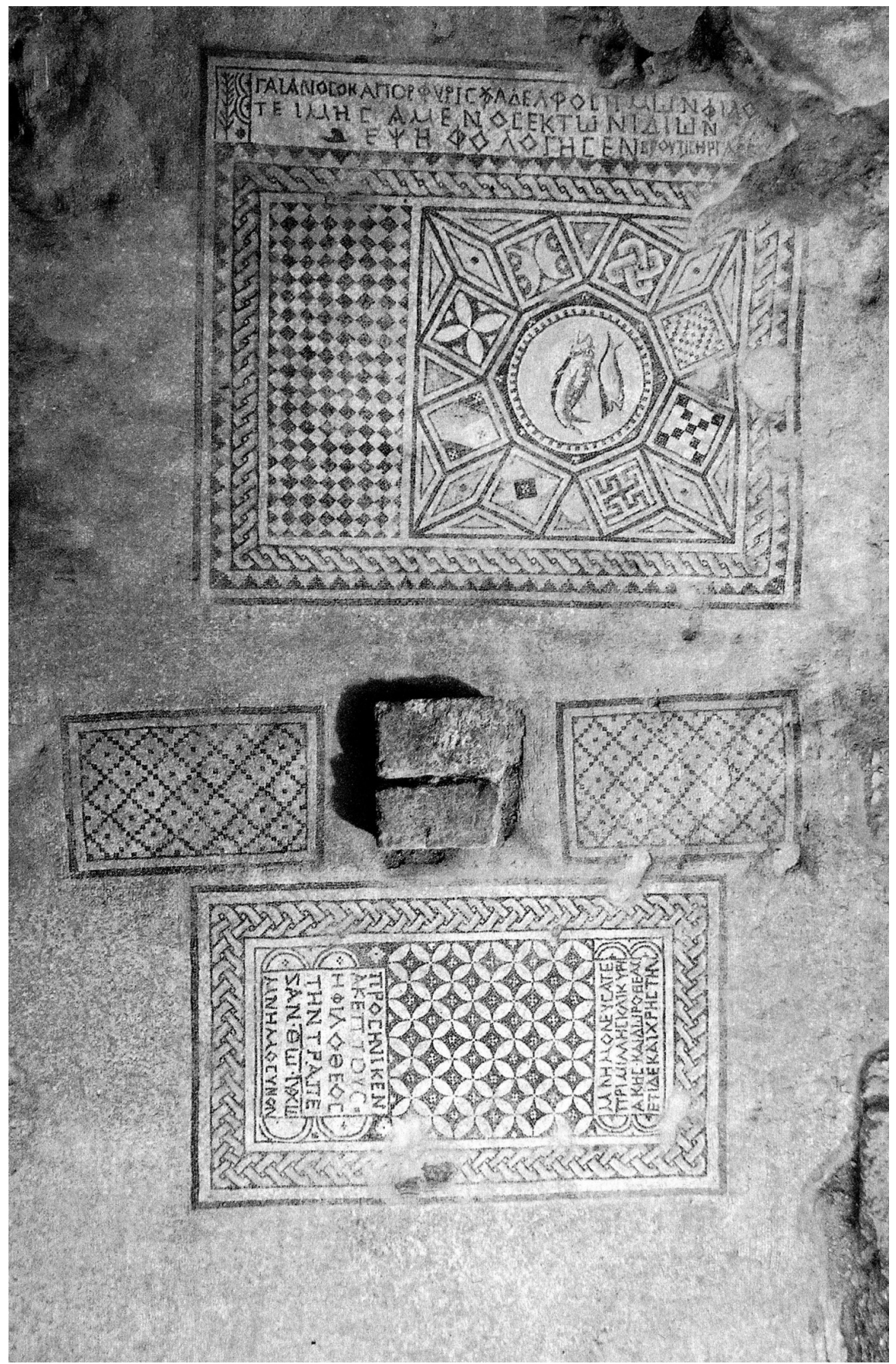

Abb. 1 Mosaikboden des christlichen Gebetsraumes von Kefar 'Othnay bei Megiddo aus dem 3. Jh. (Tepper - Di Segni 2006 [s. Anm. 4] 32) 
auf dem Ölberg, der sich mit verschiedenen Christus-Episoden verbindet, und, als Höhepunkt, an der Sterbens- und Auferstehungsstätte des Erlösers in Jerusalem, ${ }^{6}$ wo es dem Herrscher blendend gelang - besser noch als selbst in Rom -, damit auch den öffentlichen Raum spektakulär in Beschlag zu nehmen (Abb. 23).

Letzteres Heiligtum wurde recht bald nach der 324er Eroberung des Ostens geplant und noch bei Lebzeiten Constantins (†337) im Jahr 335 eingeweiht, obwohl damals die Anastasis-Rotunde mutmaßlich noch nicht errichtet war. Der Grabeskirchen-Komplex in Jerusalem ist per se das wichtigste Kultzentrum der Christenheit. Das dortige Gedenken ist ein doppeltes, werden an jenem Ort doch zwei der bedeutungsvollsten Begebenheiten der neutestamentlichen Heilsgeschichte wach gehalten, denn er umschließt zum einen, unter dem Namen Golgatha, die Kreuzigungsstätte Christi, des fleischgewordenen Gottes, der, indem er gekreuzigt wurde, die Sünden der Welt auf sich nahm, und zum anderen das Felsgrab, wo am dritten Tage die Auferstehung (Anastasis) erfolgte: ein wunderbarer Vorgang, der jedem gläubigen Christen die Hoffnung auf künftige Erweckung von den Toten und Erlösung zum ewigen Leben nährt.

Festzustellen ist also, dass Golgatha und Grab hinreichend dicht beieinander lokalisiert wurden, um sie mit einer gemeinsamen um- und überfangenden Baugruppe zu versehen. Und auch eine zweite Eigenheit ist einigermaßen zwanglos zu erläutern: dass man sich nämlich mit dem constantinischen Heiligtum mitten im Nordwestsektor des spätantiken Jerusalemer Stadtareals befindet, obwohl doch Bestattungsorte in der Antike prinzipiell außerhalb der Wohngebiete lagen. Dies lässt sich damit erklären, dass die Stadt in den drei Jahrhunderten vom Tod Christi bis zum Bau des Grabesheiligtums umstandslos über den betreffenden Ort hinauswuchs (Abb. 2, 23). In Jerusalem ergab sich somit die kuriose Gelegenheit, einen Gedächtnisbau über der Sterbestelle des dort Verehrten, des Märtyrers aller Märtyrer, nämlich für den inkarnierten Gott selbst, innerbalb der Stadt zu errichten und somit - dies ist eine ausgesprochen verheißungsvolle und chancenreiche Sondersituation - die monumental gefasste Gedenkstätte, das wichtigste Heiligtum Palästinas und der ganzen Welt, zum absoluten Zentrum des christlichen Lebens in der Stadt Jerusalem zu machen. Logischerweise fiel diese Gedächtnisfunktion mit der Kathedralfunktion zusammen: An der durch Christus geheiligten Stätte erhielt auch der lokale Bischof seinen Sitz.

$\mathrm{Ob}$ es sich hier nun wirklich um die authentischen Christusstätten handelt, bleibt im übrigen für den Archäologen relativ unbedeutend; wichtig ist, dass man damals die Tradition so und nicht anders lokalisierte - und entsprechend tat dies auch Constantin, obwohl (oder weil) an der betreffenden Stelle mittlerweile

6 Hauptquelle ist Euseb. Vgl. L. Voelkl, Die konstantinischen Kirchenbauten nach Eusebius, in: Rivista di Archeologia cristiana 29 (1953) 49-66. 187-201. 

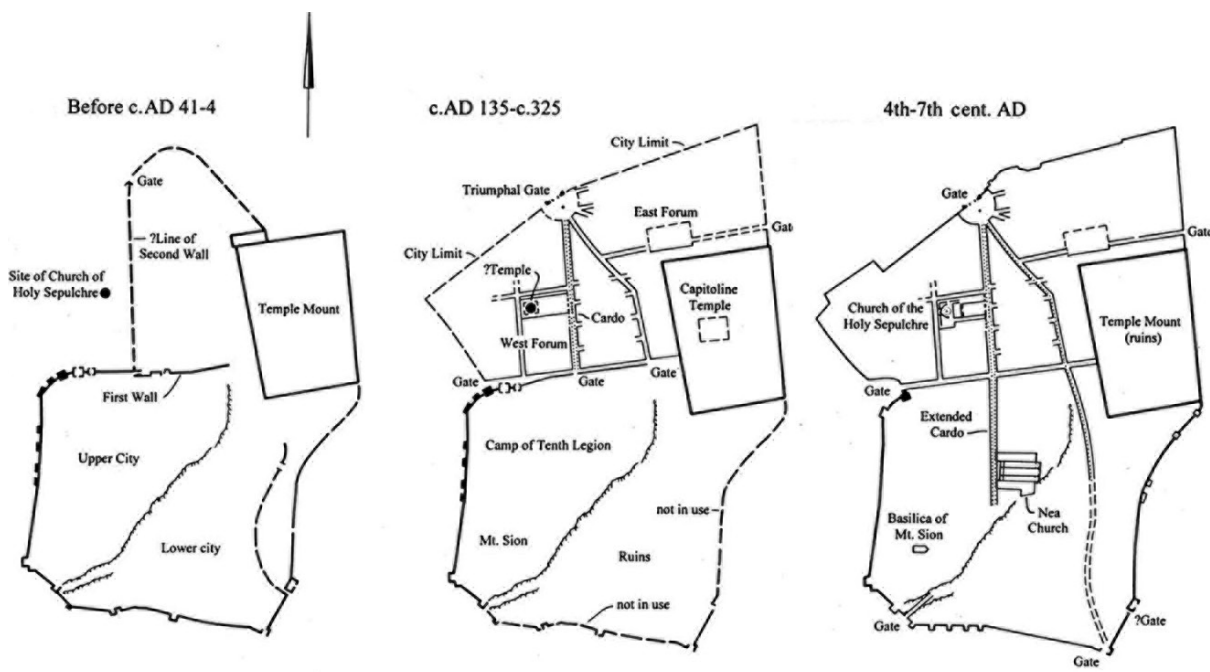

o 1000 metres

Abb. 2 Topographie Jerusalems vor 41-44, ca. 135-325 und im 4.-7. Jh. n. Chr. (Biddle, Tomb [s. Anm. 2] Abb. 60 [reduziert])

längst ein Aphrodite-Tempel gebaut worden war. Jedenfalls befahl dann der Kaiser das, was ihm in Rom mit seiner mächtigen paganen Senatorenschicht nicht so leicht gefallen wäre, nämlich den Abriss des heidnischen Tempels („Bauten des Irrglaubens“, „Kunstwerke des Trugs“, „unreine Materialien“), und alsbald kam wirklich ein Felsgrab zum Vorschein (Abb. 18 unten), ein leeres selbstredend dies war ja entscheidend -, welches man umgehend als das richtige erkannte. Nach dem überschwänglichen Bericht Eusebs zeigte sich „das verehrungswürdige und allerheiligste Zeugnis der Auferstehung des Erlösers ..., und die allerheiligste Grotte wurde zum Gleichnis für das Wiederaufleben des Erlösers".7 Da passte es gut ins Bild jener Ereignisse von 325/26, dass Constantins Mutter Helena ebenfalls - und sogar vor Ort - eine wichtige Rolle spielte, wenn auch ihr Protagonismus als Entdeckerin des Wahren Kreuzes Christi eine freilich früh formulierte Legende ist. ${ }^{8}$

Nähern wir uns dem Grabeskirchen-Komplex an (Abb. 3, 14), dem HauptHeiligtum der Christenheit, einem Gründungsprojekt der christlichen Baugeschichte, initiiert und finanziert von keinem geringeren als Kaiser Constantin selbst, der, wieder Euseb zufolge, höchstpersönlich seine Direktiven für die Bau-

7 Vita Constantini 3, 26-28 = Eusebius von Caesarea, De vita Constantini. Über das Leben Konstantins, Turnhout 2007 (Fontes christiani 83), 342-349.

8 S. Heid, Der Ursprung der Helenalegende im Pilgerbetrieb Jerusalems, in: JbAC 32 (1989) 41-71. 
gestaltung nach Jerusalem übermittelte; einer Architektur, deren Kulminationspunkt, die Anastasis, mindestens bis zum Ende des Mittelalters auch eine mächtige Vorbildfunktion für weitere Projekte in der gesamten Christenheit ausgeübt hat; kurz: einem einzigartigen, kapitalen, unvergleichlich einflussreichen Denkmal, von dessen frühchristlicher Ausgangssubstanz leider gegenwärtig, bald 13/4 Jahrtausende nach der Entstehung der Anlage, nur noch wenig vorhanden ist - so sehr haben jüngere Ereignisse für Veränderungen gesorgt, namentlich dasjenige von 1009.

Die Anlage besteht heute im Wesentlichen aus drei Bereichen (Abb. 4-6). Da ist erstens im Westen eine teils noch spätantike große zweischalige Rotunde von $33 \mathrm{~m}$ Durchmesser mit innerem Säulenkranz und dem Herrengrab in ihrem Zentrum, einer kleinen, völlig verbauten Struktur des frühen 19. Jhs. (Abb. 16); da sind zweitens die östlich anschließenden, ganz überwiegend kreuzfahrerzeitlichen Partien, bestehend aus dem griechisch-orthodoxen Katholikon mit seinem Chor und Chorumgang und den sogenannten, Querschiffen', das Ganze drittens auf einer tieferen Ebene noch nach Osten verlängert um die ,Helena-Kapelle‘ mit der Grotte, wo Constantins Mutter die Vera Crux gefunden haben soll. Hervorzuheben ist die Stelle des Golgatha- oder lateinisch des Calvarien-Felsens nahe dem an der Südseite gelegenen Zugang.

Dieses ganze Gefüge hat nur noch wenig mit den ursprünglichen, constantinisch-frühchristlichen Intentionen zu tun, und so befindet sich auch nur noch einiges wenige an der Stelle und in der Funktion, für die es seinerzeit im 4. Jh. errichtet wurde. Jene enorm prächtige Komplexanlage Constantins mit fünfschiffiger Gottesdienstbasilika ${ }^{9}$ und zweischaliger Grabesrotunde stand 614 bei der persischen Eroberung Jerusalems und 966 bei einem muslimischen Angriff in Flammen, um jeweils anschließend wiederhergestellt zu werden. Als der irreversible Schlag folgte schließlich im Jahr 1009 die radikale Zerstörung von Seiten des Kalifen al-Hāakim, welchem die Basilika vollständig und der Rundbau vor allem in seinen inneren Teilen zum Opfer fielen. Von den alten Komponenten wurde nur letzterer - stark verändert - wiederaufgebaut.

Ein Blick auf die Baugesamtheit, wie sie sich nach weithin solide gesicherten Forschungsresultaten ursprünglich darstellte - also gemäß dem constantinischen Konzept und nach Vollendung der Rotunde, die erst nach Constantins Tod fertig wurde -, erweist das Ensemble (Abb. 3) als eine ganz frühe christliche Auseinandersetzung mit dem die weiteren Jahrhunderte hindurch aktuell bleibenden

9 Der Terminus ,Basilika' kommt hier und im Folgenden ungeachtet der Frage zum Einsatz, ob denn diese Kirche überhaupt unserer geläufigen Vorstellung von einer ,christlichen Basilika' entsprach, ob also das Hauptschiff mit Hilfe von Lichtgaden überhöht war (unsere Abb. 3, 14, 15, 23) oder ob ein großes gemeinsames Satteldach das Langhaus deckte (Abb. 13). Vgl. Anm. 16. 


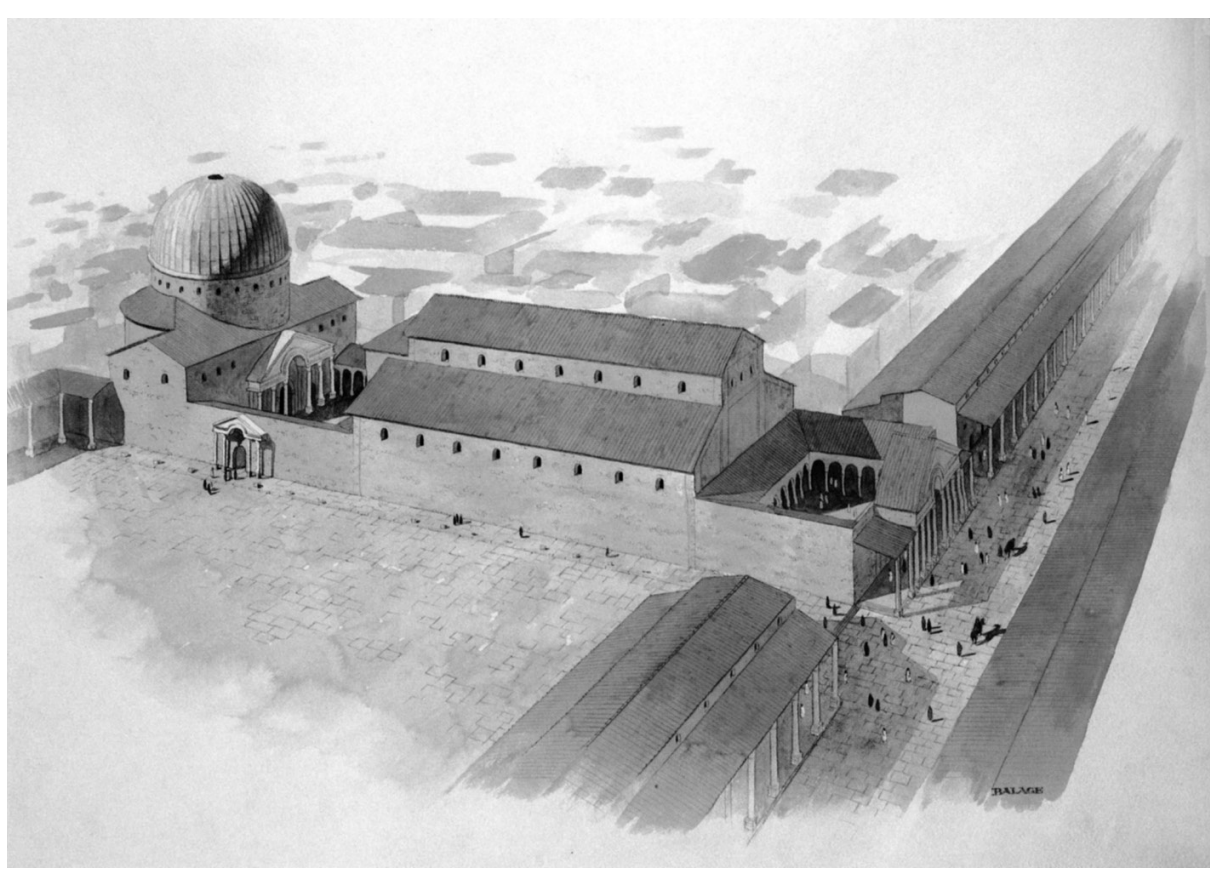

Abb. 3 Zeichnerische Vision des frühchristlichen Grabeskirchen-Komplexes am Jerusalemer Cardo von Süden.

(Cradle of Christianity, Ausstellungskatalog Jerusalem 2000, 38)

Thema des Verhältnisses von Richtungs- und Zentralbau. Im Unterschied zu späteren Lösungen, bei denen man beides durch kreuzförmige Addition miteinander verband (Simeons-Heiligtum in Syrien) oder sogar in eins setzte (Hagia Sophia), schuf man hier ein Miteinander, wobei die Beteiligung eines Rundbaues an sich nichts Neues war (man kannte dies schon vom kaiserlich-constantinischen Mausoleumsbau an der Marcellinus-und-Petrus-Kirche vor den Toren Roms), dessen Ausformung als ein Umgangsrundbau mit hoher Kuppel aber einen großen gestalterischen Fortschritt darstellte. Ob freilich das Konzept mit einem den baulichen Kern begleitenden und mit jenem kommunizierenden deambulatorium hier als der ausschlaggebende Erstentwurf innerhalb der christlichen Architekturgeschichte anzusprechen ist oder ob dieses Vorrecht dem stadtrömischen Mausoleum der Kaisertochter Constantina aus den 350er Jahren gebührt, ist nicht entschieden. ${ }^{10}$

10 B. Brenk, Der Kultort, seine Zugänglichkeit und seine Besucher, in: Akten des XII. Internationalen Kongresses für Christliche Archäologie [Bonn 1991] = JbAC, Ergbd. 20,1, Münster 1995, 97 sieht die Priorität, geknüpft an die Neuerung, das Grab ins Zentrum zu stellen, bei der Anastasis: „Hier aber drehte sich alles förmlich um das 
Man schuf also im Osten der Baugesamtheit die Gottesdienstbasilika ${ }^{11}$ mit ihrer gewesteten Apsis, im Westen als Ziel- und Höhepunkt die Rotunde, dazwischen ein verbindendes Atrium mit dem Golgatha-Felsen, das Ganze noch vermehrt um Nebenräume einschließlich eines Baptisteriums (dafür Abb. 14) sowie um ein weiteres axiales Atrium, nämlich einen Vorhof im Osten, der seinerseits über drei Tore sowie über Stufen die Kommunikation mit dem Cardo Maximus, der großen, portikengesäumten Nord-Süd-Achse Jerusalems, herstellte. Die monumentale, reihende Inszenierung dieser gewesteten Baugesamtheit im Verhältnis zum Cardo - völlig anders, als es die heutige etwas ,eckige‘ und ziemlich unelegant arrangierte Seiten-Annäherung an ein verbautes, geostetes RumpfEnsemble (Abb. 4-6) empfinden lässt- entnimmt man recht deutlich den zeichne-

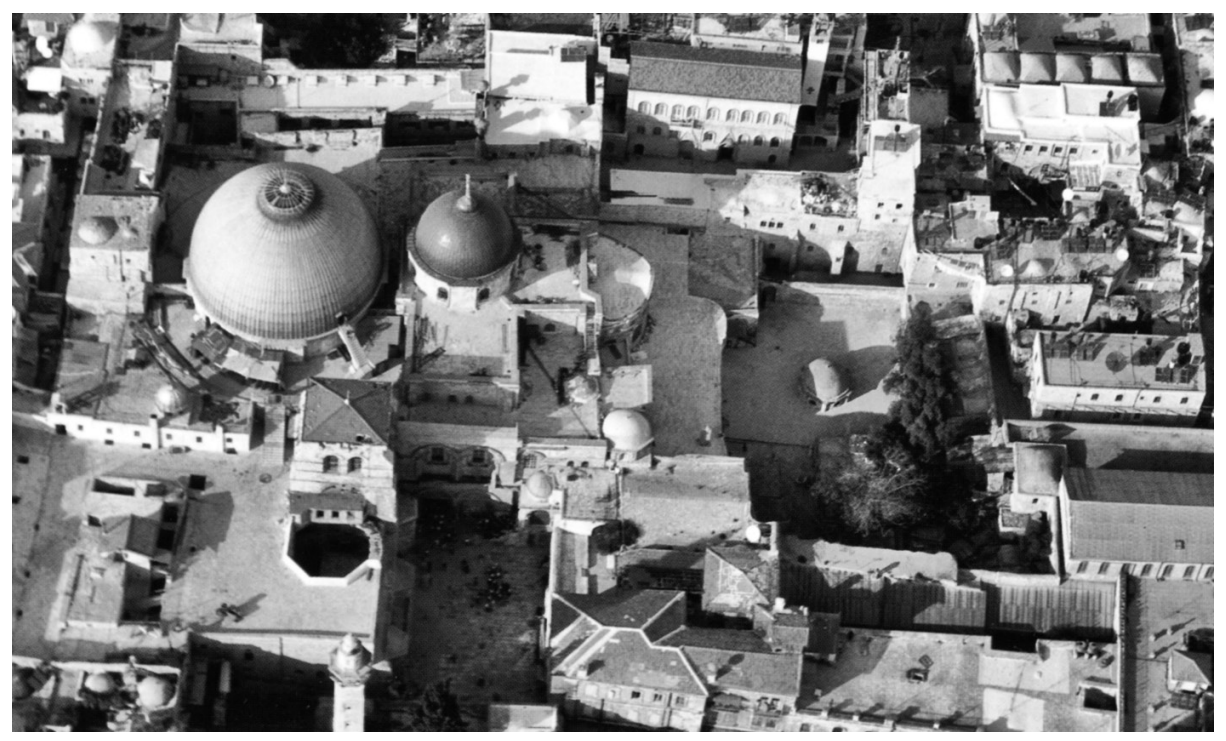

Abb. 4 Das Baugefüge heute. Luftaufnahme von Süden.

(Biddle, Tomb [s. Anm. 2] Abb. 3)

Grab Christi. Die neue Aufgabe erheischte eine neue Bauform: Erstmals ist ein Zentralbau mit Stützenkranz errichtet worden, weil es darum ging, das Grab Christi frei zu stellen, allseitig sichtbar und umschreitbar zu machen. ... Der Umgang eignete sich für Prozessionen um das Grab und gleichzeitig wurde das Grab Christi durch den Säulenkranz den Pilgern entrückt."

11 Diese in erster Linie als religiöser Versammlungsraum und zwar fraglos auch als Kathedral- und mithin als ordentliche Messfeierkirche dienende Komponente des architektonischen Gefüges figuriert schon in der Spätantike gern als das ,Martyrion“. Im vorliegenden Beitrag wird jene Benennung, die im modernen Sprachgebrauch eher den Grabbau eines Märtyrers evoziert, nicht gebraucht, um Verwechslungen mit der Anastasis-Rotunde auszuschließen. 


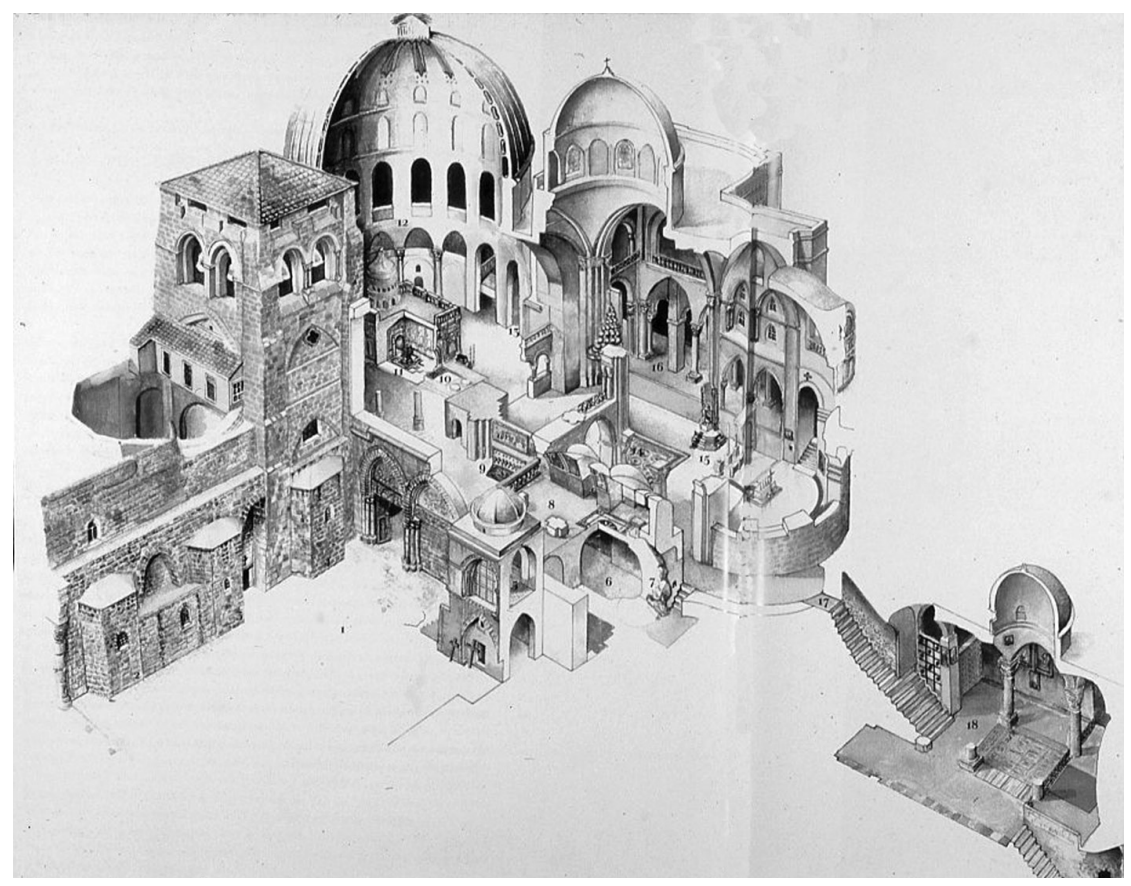

Abb. 5 Das Baugefüge heute. Zeichnerischer Einblick.

(Martin Biddle et al., Die Grabeskirche in Jerusalem, Stuttgart 2000, 70f.)

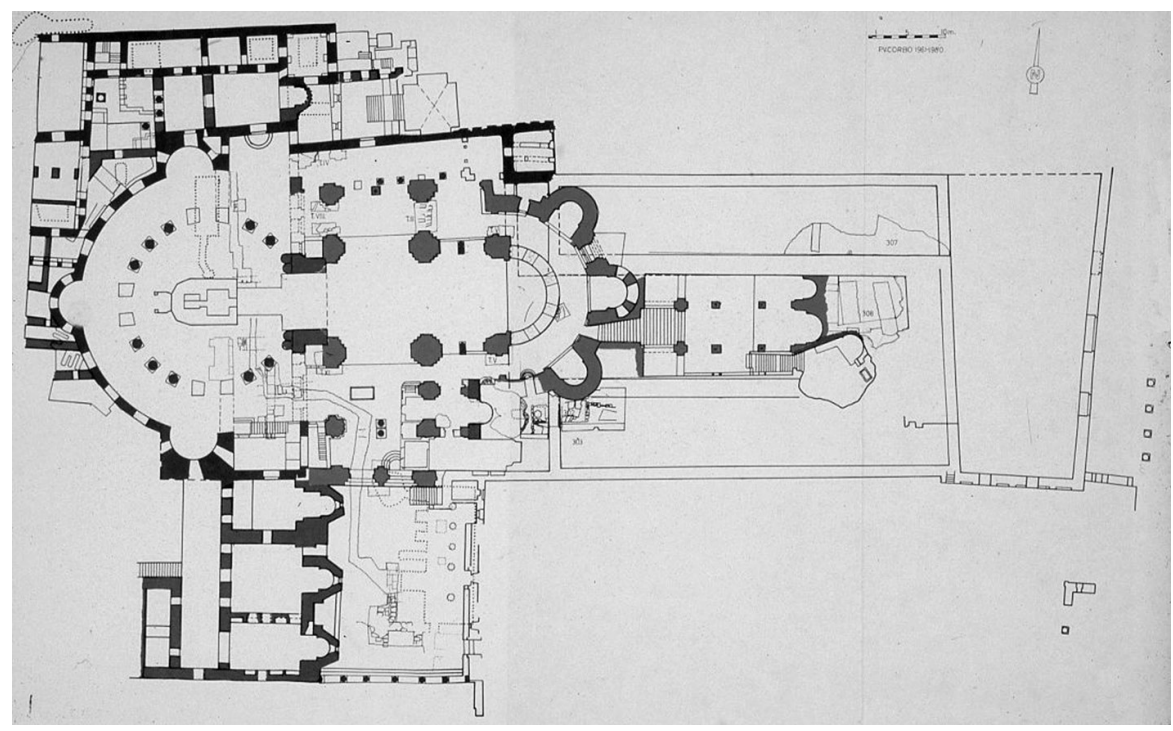

Abb. 6 Das Baugefüge heute. Grundriss.

(Corbo, Sepolcro [s. Anm. 2] II Taf. 1) 


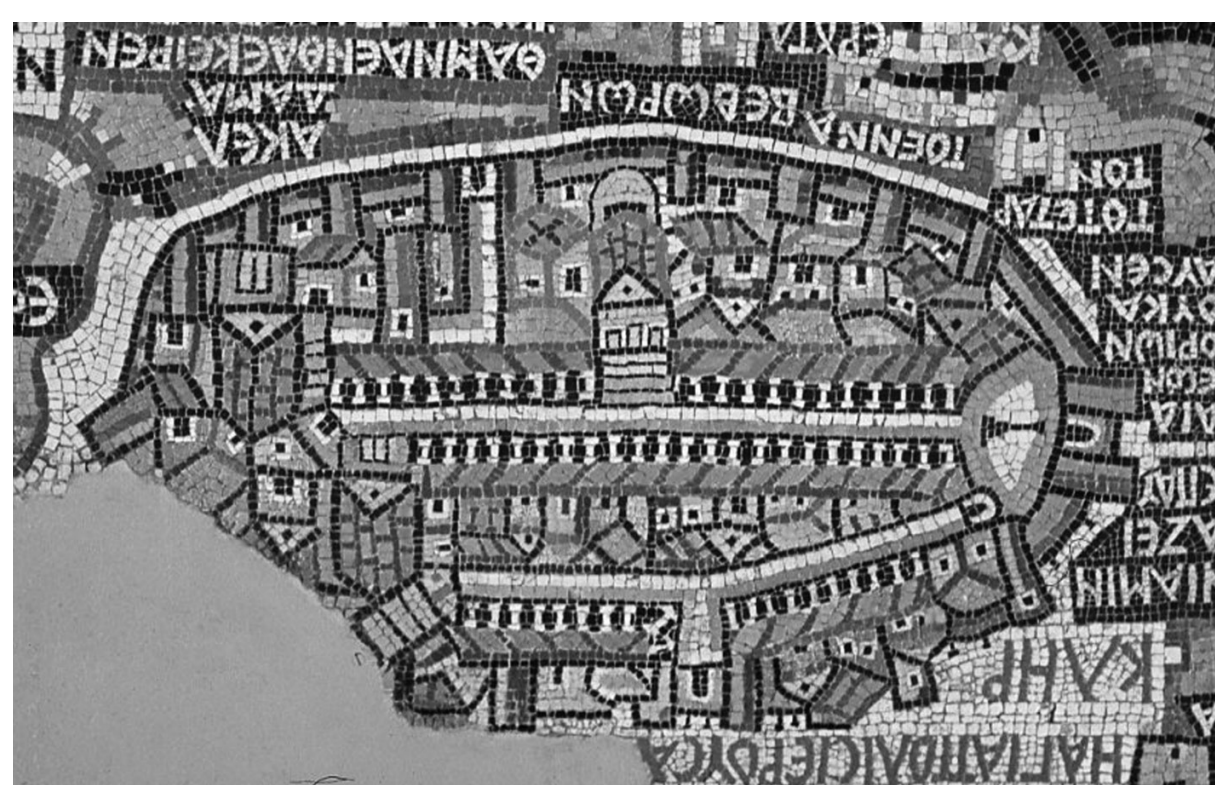

Abb. 7 Mosaikkarte des Heiligen Landes in Madaba / Jordanien aus dem 6. Jh. (Göttinger Replik), um $180^{\circ}$ gedreht (Norden ist rechts): Jerusalem mit dem Cardo und dem Grabeskirchen-Komplex im Zentrum. (Photo: Fittschen)

rischen oder plastischen Rekreationen Jerusalems in der Spätantike (Abb. 9, 23). Doch selbst auf der die Mosaikkarte von Madaba aus dem 6. Jh. beherrschenden

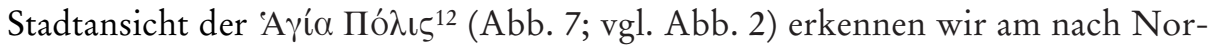
den durchlaufenden Cardo den gewesteten constantinischen GrabeskirchenKomplex mit basilikalem Teil und davon klar abgesetztem Rundbau über dem Christusgrab, welcher ausweislich der hier benutzten gelben Mosaiksteine eine vergoldete Kuppel besaß. Der Begriff ,Komplexanlage` ist im Übrigen ein fester Ausdruck, welcher speziell die im constantinischen Kirchenbau eingeführte Neuerung anspricht, große Kultarchitekturen durch das Hintereinanderordnen einzelner umfangender und überfangender Räume zusammenzufügen - so etwa auch die frühchristliche Peterskirche in Rom oder eben, als ein noch differenzierteres Beispiel, die Jerusalemer Bauformation: Treppe und Türen - Atrium mit Säulenportiken ${ }^{13}$ - Basilika - Atrium mit Säulenportiken - Anastasisrotunde. ${ }^{14}$

12 H. Donner, The Mosaic Map of Madaba. An introductory guide, Kampen 1992, 87-94, bes. 90 .

13 Die Säulengänge werden von Euseb eigens erwähnt: Vita Constantini (s. Anm. 7) 3,39 = S. 358f.

14 Dass diese longitudinale Aufreihung sich lediglich den Platzzwängen einer schmalen Bauparzelle verdankt hätte (so Brenk, Kultort [s. Anm. 10]), will angesichts der impe- 
Das Ganze war, wie gesagt, zum Höhepunkt des Grab-Rundbaues hin gewestet, so wie es der damals fast ausnahmslos befolgten Übung entsprach und wie es sich auch zwanglos anbot, wenn die Baufolge vom Cardo aus zugänglich sein und sich emphatisch steigern sollte.

Jene eindrucksvolle Aufreihung nacheinander abschreitbarer, sich steigernder Elemente hob sehr viel weiter im Osten an als das gegenwärtig existierende Baugefüge (Abb. 3, 4). Der Golgatha-Felsen lag damals auf halber Strecke unter freiem Himmel in einer Ecke des Zwischenatriums (Abb. 8-10). Fast schon das östliche Ende markiert er dagegen, gänzlich verbaut, in dem sehr viel kürzeren kreuzfahrer- bis jetztzeitlichen, durch wiederholte Zerstörungsereignisse und Neu- oder Umbauten vollkommen umgeprägten und überdies nun nach Osten hin ausgerichteten Grabeskirchen-Konglomerat (Abb. 5, 6). Wer dieses heute seitlich aus dem Gewimmel der Altstadtgassen erreicht, hat nach dem Eintreten seine Mühe, das Ganze recht zu verstehen: ein uneinheitliches Gemisch aus wenigen spätantiken Resten und für den Laien weithin unübersichtlichen jüngeren Ergänzungen, unter denen allein die kreuzfahrerzeitliche Substanz im gegenwärtigen, recht überladenen Gesamteindruck ein gewisses Eigengewicht erlangt.

Dagegen war die unmittelbar dem Cardo angeschlossene Formation des 4.Jhs. (Abb. 3, 8-10) von Großzügigkeit, Würde und Klarheit geprägt. Recht gute Kenntnis davon geben uns zum einen schriftliche Zeugnisse, allen voran der Bericht Eusebs aus der Vita Constantini. In ihm wird ein Schreiben des Kaisers mit Anweisungen an den Jerusalemer Bischof Makarios zitiert, dem Constantin einschärft, dass hier ein extrem reich ausgestattetes Heiligtum entstehen solle, so „dass alle anderen Gebäude, die sich in jeder Stadt durch ihre Schönheit auszeichnen, von diesem übertroffen werden ". ${ }^{15}$ Bemerkenswert ist, dass Euseb die Gesamtanlage von Westen nach Osten durchgeht, also das Wichtigste, die zu seiner Zeit augenscheinlich noch nicht mit einer großen Umgangs- und Kuppelrotunde überfangene Stätte des Salvatorgrabes in ziemlich summarischer, unpräziser Schilderung an den Beginn stellt, dann das Zwischenatrium nennt und über die Basilika zum östlichen Vorhof gelangt. Nur bei der Basilika ist seine Beschreibung verhalten detailliert, wenn auch nicht archäologisch exakt. Er legt großen Wert auf die Pracht der Materialien - bunter Marmor, Intarsienarbeiten -, bringt dann jedoch einige wichtige Züge der Architektur, etwa dass es eine getäfelte Decke mit Schnitzarbeiten und Vergoldung gab. „Auf beiden Seiten der doppelten Säulenhallen, im oberen und im unteren Stock, dehnten sich Zwillingssäulenumgänge in der Länge der Kirche aus"; das Mittelschiff begleiteten also je zwei

rialen Machtfülle und der vergleichend heranzuziehenden Disposition des Petrusheiligtums in Rom nicht recht einleuchten.

15 Vita Constantini (s. Anm. 7) 3, 30-32 = S. 350-355. 


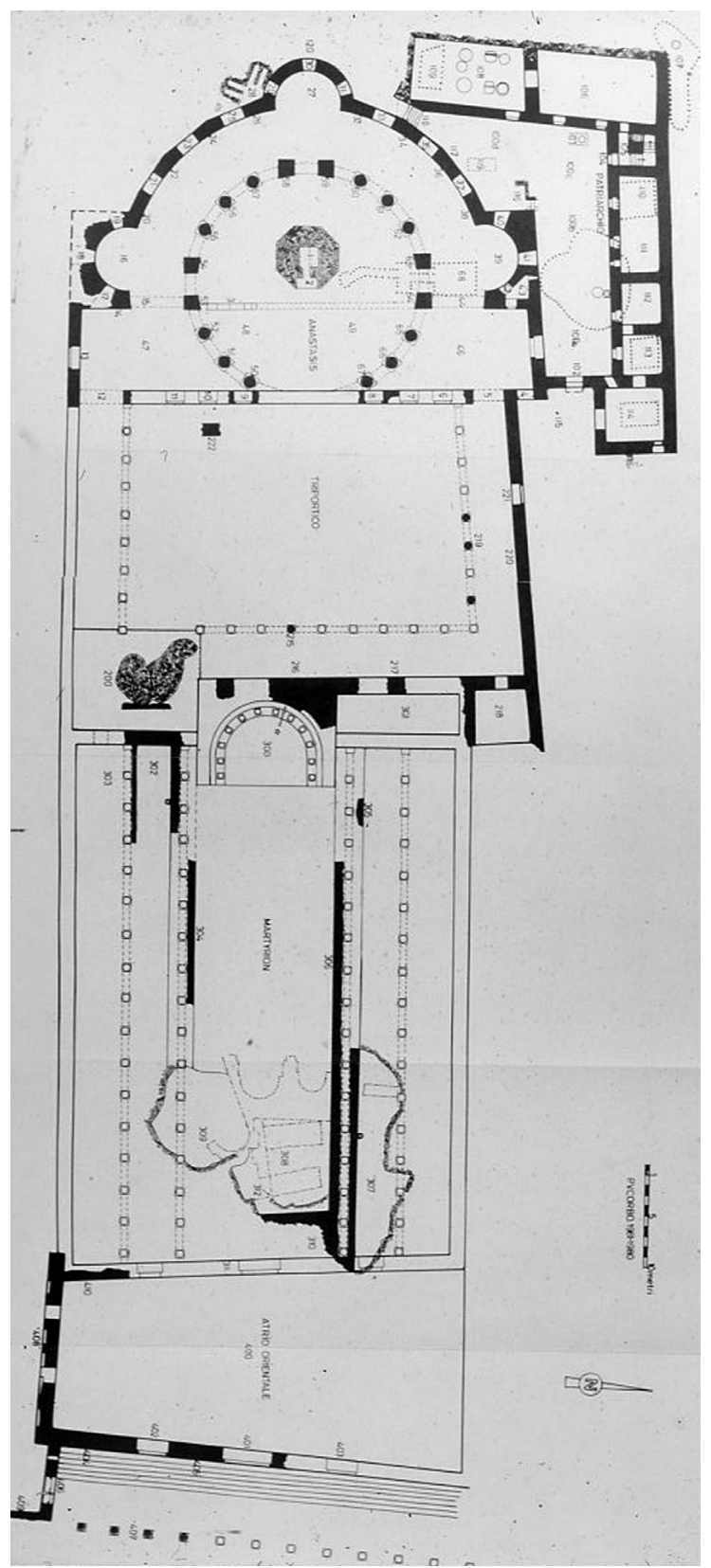

Abb. 8 Plan der frühchristlichen Anlage. Die archäologisch kontrollierten Partien wurden im Grundriss schwarz markiert. Im östlichen Vorhof müssen dort Säulenportiken ergänzt werden, die zwar offenbar nicht dokumentiert, aber von Euseb erwähnt sind. (Corbo, Sepolcro [s. Anm. 2] II Taf. 3) 


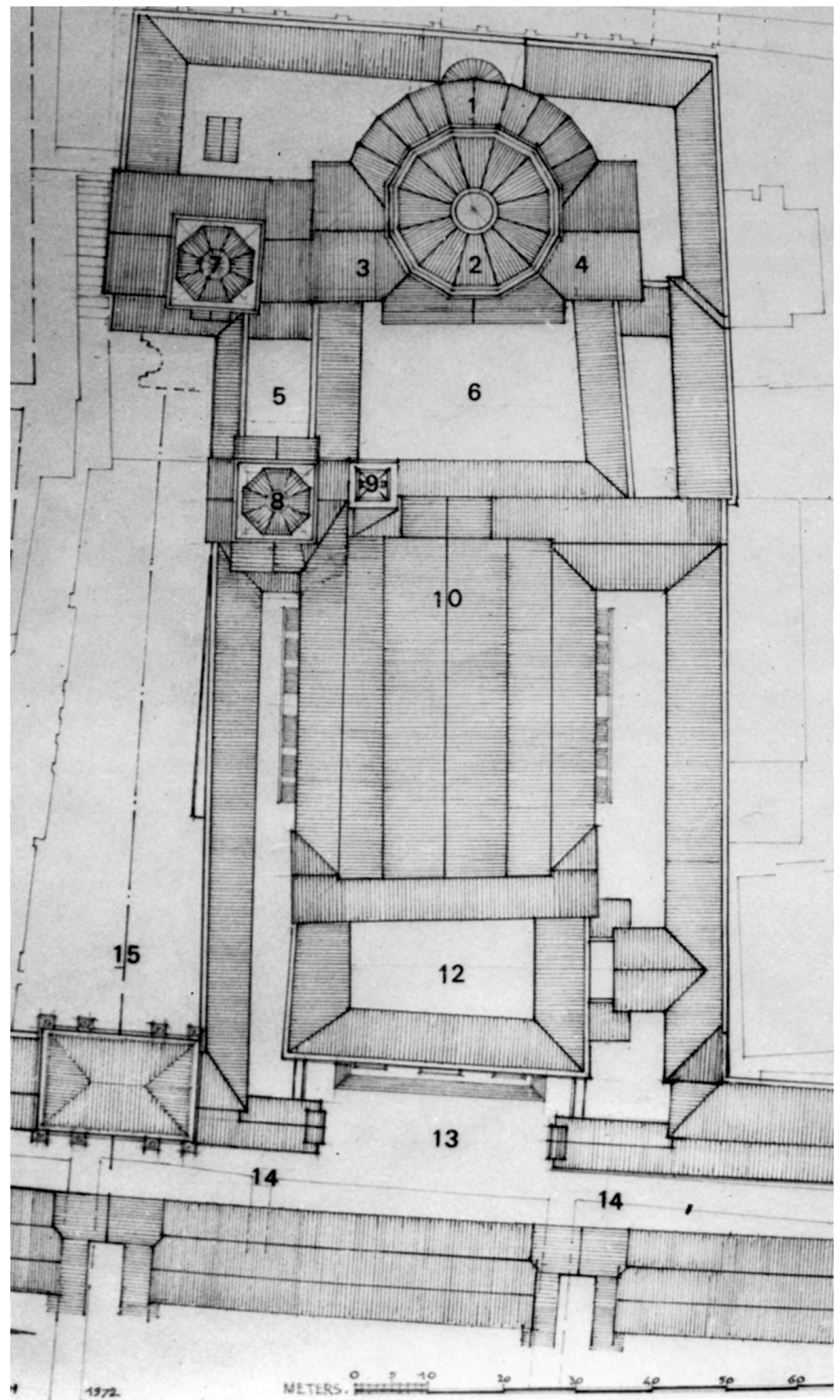

Abb. 9 Vermutete Dachaufsicht der frühchristlichen Anlage.

(Coüasnon, Church [s. Anm. 2] Taf. 15) 


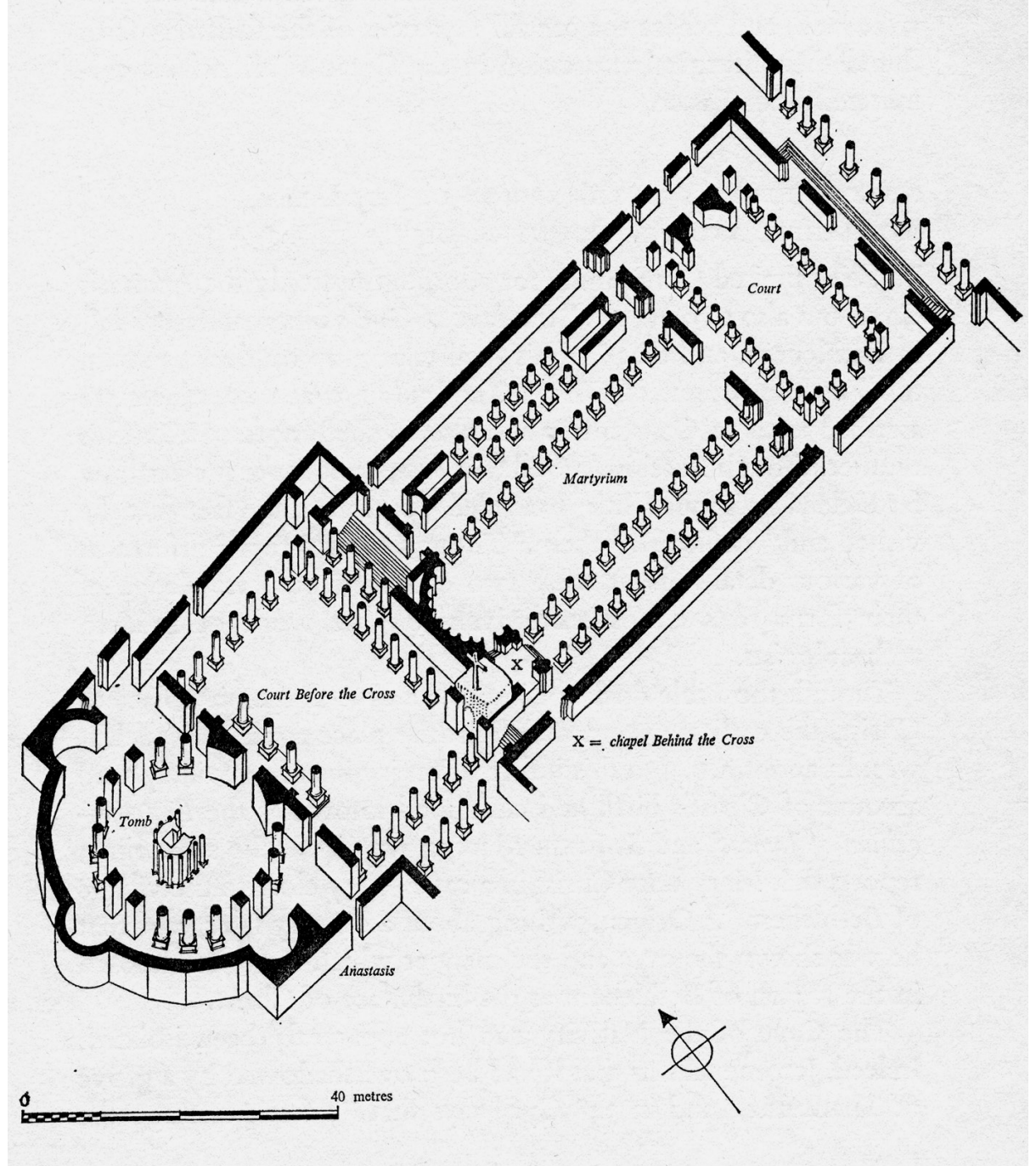

Abb. 10 Axonometrie der frühchristlichen Bauformation.

(J. Wilkinson, Egeria's travels, London 1971/73, 45) 


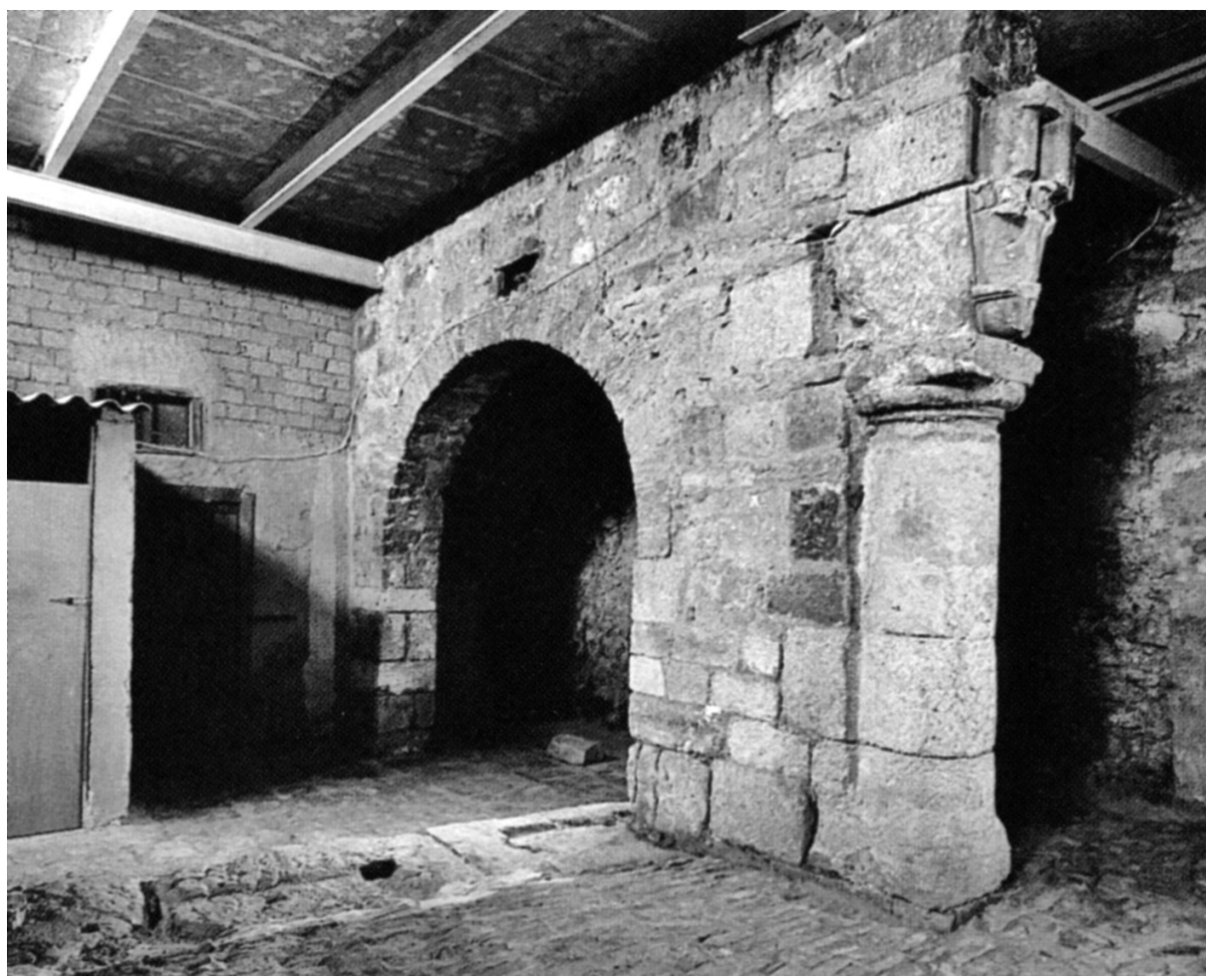

Abb. 11 Teilweise noch spätantike aufgehende Reste der Eingangswand mit Zugängen zum Vorhof am Cardo. (Krüger, Grabeskirche [s. Anm. 25] Abb. 46)

Seitenschiffe mit Emporen (Abb. 10, 13). ${ }^{16}$ Zudem „war das Haupt des Ganzen halbkugelförmig, an der Spitze des kaiserlichen Hauses angeordnet, das zwölf Säulen umkränzten, die gleiche Zahl wie die der Apostel“, womit die Wandsäulen aufweisende Apsis einschließlich ihres sphärischen Gewölbes angesprochen ist. ${ }^{17}$

Als ein zweites wichtiges Textzeugnis ist der in den frühen 380er Jahren abgefasste Reisebericht der wahrscheinlich hispanischen Pilgerin Egeria zu nen-

$16 \mathrm{Ob}$ es sich um eine geläufige ,christliche Basilika' mit abgesetzten und durchfensterten Obergaden handelte wie im Falle der älteren großen stadtrömischen Projekte: der Laterankathedrale aus den 310er Jahren und der Peterskirche aus den Jahren um und nach 320 (H. Brandenburg, Die frühchristlichen Kirchen Roms vom 4. bis zum 7. Jahrhundert, Regensburg 2004, Zeichnungen S. 261, 278), ist ungeklärt. Die Mehrzahl unserer Abbildungen vermutet ersteres, doch ist vor kurzem auch die Vision mit zwei bis zum First durchgehenden Dachschrägen wiederbelebt worden, B. WeberDellacroce - W. Weber, Grabeskirche in Jerusalem (Modell), in: Konstantin der Große, Ausstellungskatalog Trier, Mainz 2007 Nr. II.2.25 (auf CD-ROM).

17 Vita Constantini (s. Anm. 7) 3, 33-40 = S. 354-359. 
nen, einer gottgeweihten Frau, deren höchst lebendige Bemerkungen allerdings weniger für die Gestalt des Heiligtums als für das liturgische Geschehen in ihm bedeutsam sind. ${ }^{18}$

Eine komplementäre Erkenntnisquelle bilden die wenn auch etwas schütteren archäologischen Aufschlüsse, welche vornehmlich durch Virgilio C. Corbo in den 1960er und 70er Jahren an verschiedenen Stellen unter der ursprünglichen Anlage gewonnen werden konnten (Abb. 8) und die unser Bild nun ganz handgreiflich mitbestimmen. ${ }^{19}$ Vorhanden und ergraben worden ist nicht viel, aber immerhin doch Entscheidendes, um heute Sicherheit über wesentliche Merkmale der Gestalt, vor allem des Grundrisses, zu besitzen. So fand man noch aufgehende Teile der Ostwand, also der Eingangswand des Vorhofs mit Durchgängen, die die Verbindung vom Cardo herstellten (Abb. 11). Wichtig war ferner die Lokalisierung des südlichen Fundamentzuges unter dem Mittelschiff, eine veritable Grundmauer von beträchtlicher Eigenhöhe, die sich aufwärts verjüngt (Abb. 12). Die oberste Steinlage dieser Mauer war also der Stylobat, auf dem sich einst die schiffstrennenden Säulen erhoben. Auch die Apsis der fünfschiffigen konstantinischen Basilika ist nachgewiesen durch einen Abschnitt ihres Runds vor der geraden Weststirn des Baues, die daneben noch ansatzweise nach Norden weiterzieht. Weiter westlich überdauert eine Basis der Triportikus, also jenes Säulenganges, der das Zwischenatrium an drei Seiten einfasste, bei dessen Südostecke unterbrochen durch die Fassung des Golgatha-Felsens (wie auch immer diese Fassung und respektvolle Absonderung im Einzelnen gelöst worden sein mag). Von der Rotunde schließlich sind über $10 \mathrm{~m}$ hohe Partien der Umfassungswand original erhalten.

Jenseits außerhalb an der Südseite ist in einem der hier beigegebenen Rekonstruktionsvorschläge (Abb. 14) eine für die Taufe bestimmte Baugruppe angenommen worden. ${ }^{20}$ Dass es eine solche tatsächlich gab, ist schon durch das Zeugnis des anonymen ,Pilgers von Bordeaux ${ }^{6}$ aus dem Jahre 333 gesichert ${ }^{21}-$ und im Übrigen auch naheliegend, nicht nur, weil wir später bei etlichen Pilgerheiligtümern Baptisterien finden, sondern im vorliegenden Fall schon darum, weil es sich hier doch auch um eine Kathedrale handelte.

18 It. 24ff. = G. Röwekamp (Hrsg. u. Übers.), Egeria, Itinerarium. Reisebericht, Freiburg u.a. 1995 (Fontes christiani 20), 224ff.

19 Corbo, Sepolcro (s. Anm. 2).

$20 \mathrm{Vgl}$. A. J. Wharton, The Baptistery of the Holy Sepulcher in Jerusalem and the politics of Sacred Landscape, in: DOP 46 (1992) 313-325.

21 Itinerarium burdigalense 594, 2-4 = Itineraria et alia geographica, Turnhout 1965 (Corpus Christianorum, Series Latina 175), 17: „... ibidem modo iussu Constantini imperatoris basilica facta est ... habens adlatus excepturia, unde aqua levatur, et balneum a tergo, ubi infantes lavantur.“ 


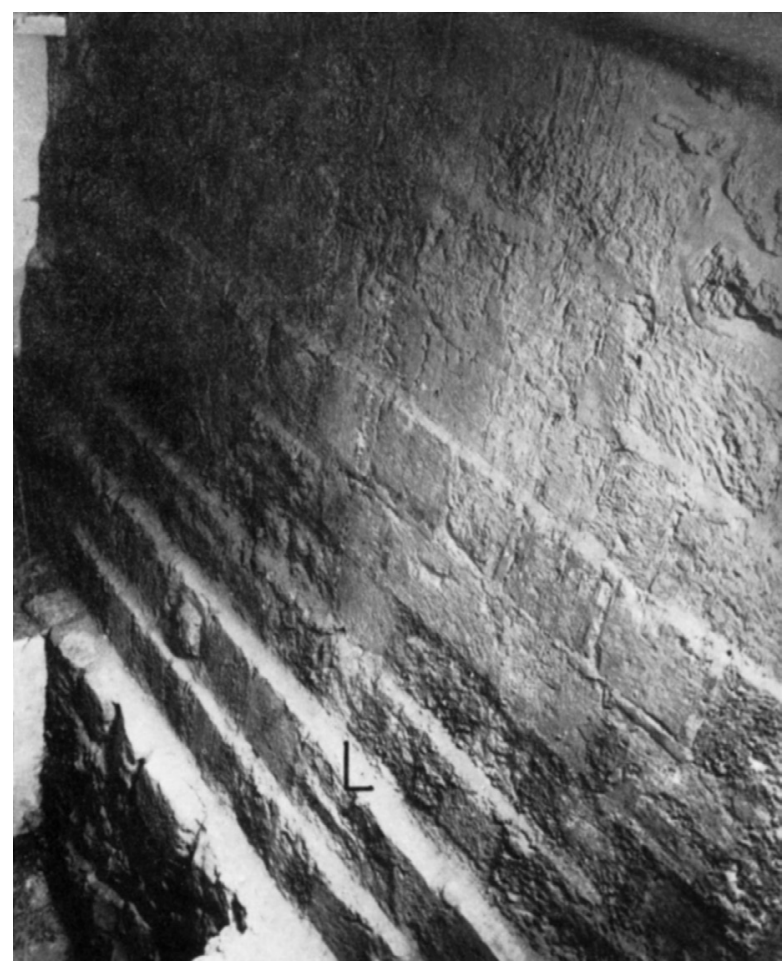

Abb. 12 Grundmauer der südlichen Säulenreihe am Mittelschiff. (Corbo, Sepolcro [s. Anm. 2] III Photo 101)

Wie das Areal an der Westseite des Zwischenatriums, also um die Stelle des Heiligen Grabes herum, anfänglich aussah, ist nicht näher bekannt; jedenfalls legt Eusebs und des ,Pilgers von Bordeaux' Schweigen über eine Rotunde nahe, dass die definitive Gestaltung verzögert erfolgte. Von manchen Autoren wurde für die erste Etappe eine - runde oder schon gegliederte - das Grab markierende Ädikula unter freiem Himmel vermutet, welche nach Westen zu von einer weiten Exedra des Westatriums umschlossen gewesen wäre - wobei sich die dringende Frage stellen würde, ob man eine solche Anordnung nicht vielleicht von vornherein nur als ein Provisorium gedacht hätte. Es könnte ja von Beginn an zumindest die Planung bestanden haben, dem sepulcrum eine adäquate, eindrucksvolle architektonische Fassung $\mathrm{zu}$ verleihen. ${ }^{22}$ Für dauerhaften Bestand ausgeführt

22 Coüasnon, Church (s. Anm. 2), 3f., 14-17, 21-23 Taf. 7 geht auf ältere Stimmen in diesem Sinne ein (darunter R. Krautheimer, Early Christian and Byzantine Architecture, Harmondsworth 1965, Abb. 16) und vermutet auch selbst in der ersten Phase eine Lösung mit dem Grab unter freiem Himmel. - Zuletzt sind Weber-Dellacroce Weber (s. Anm. 16) darauf zurückgekommen; sie handhaben das Argument der tat- 


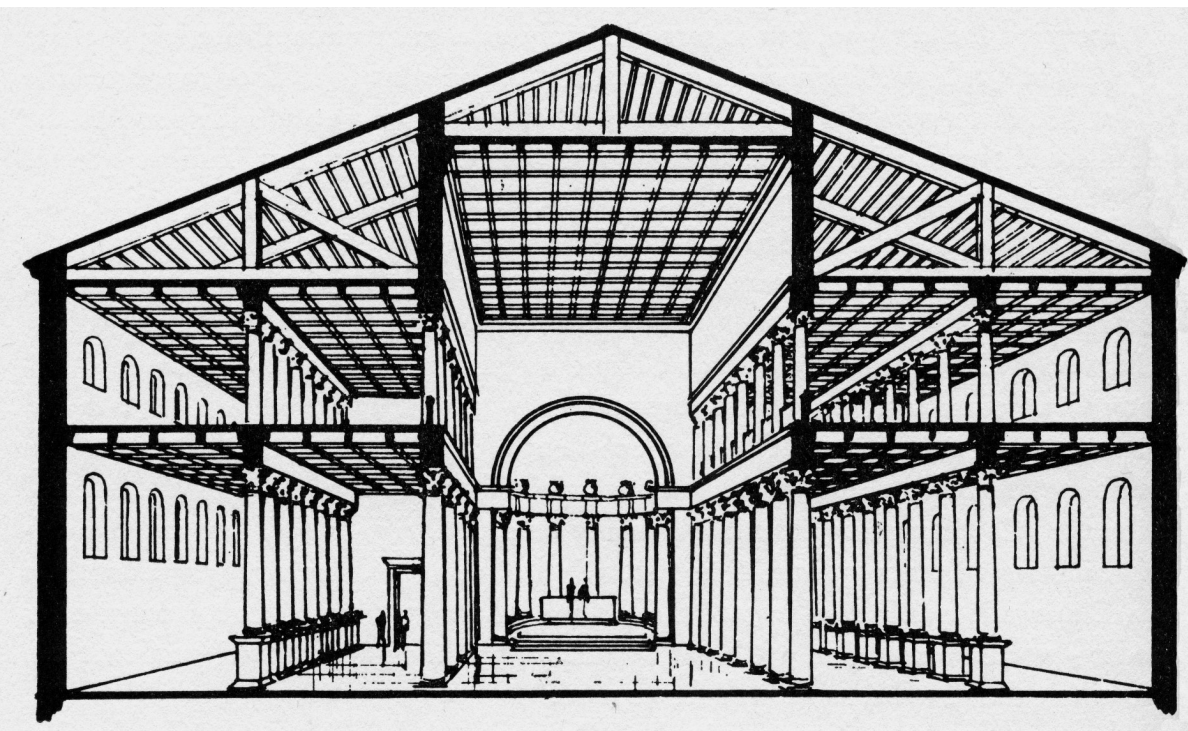

Abb. 13 Zeichnerischer perspektivischer Rekonstruktionsversuch der Basilika nach Westen (Lampl). (Krautheimer, Architecture [s. Anm. 22] Abb. 17)

wurde dann der zweischalige Kuppelrundbau. Dieser verfügte über keinen kompletten Umgang, sondern wies einen solchen nur zur Hälfte seiner Zirkumferenz auf, während nach Osten, zum Triportikus-Atrium hin, zwei erweiterte Übergangsräume existierten.

Aus alledem fügt sich ein mehr oder weniger solides Bild. Natürlich muss man jedem Versuch, die Gesamtanlage zeichnerisch oder im Modell zu rekonstruieren, immer zugutehalten, dass der dabei wirksam werdende Zwang zur Konkretion auch einmal Konjekturen und Verlegenheitslösungen an architektonischen Partien gebiert, die man redlicherweise lieber im unklaren ließe - so bei den Stützenfolgen der Basilika, die sowohl Bögen als auch aufliegende Gebälke getragen haben können (Abb. 13,15). Ob die Atriumsfassade der Rotunde durch einen monumentalen Mittelgiebel über mehreren Säulen akzentuiert war (Abb. 10, 14, 15), steht dahin. Manches an dem, was weniger für die Fachwelt und mehr für ein größeres Publikum elaboriert worden ist, um der Vorstellung vom Grabeskirchen-Komplex visuell aufzuhelfen, schießt auch unnötig über das Ziel hinaus - etwa wenn in einem der Modelle an der südlichen Langhauswand eine eigenwillige, $u$.W. durch nichts gedeckte Lösung mit Estrade und einer im verdickten Mauermassiv steckenden Fünf-Bogen-Vorhalle (Abb. 14) geboten

sächlich vorhandenen Exzentrizität des Salvatorgrabes in Bezug auf den Stützenkranz. Dagegen scheint Brenk, Kultort (s. Anm. 10) zu implizieren, dass die Anastasis-Rotunde so bereits zum constantinischen Erstprojekt zählte. 


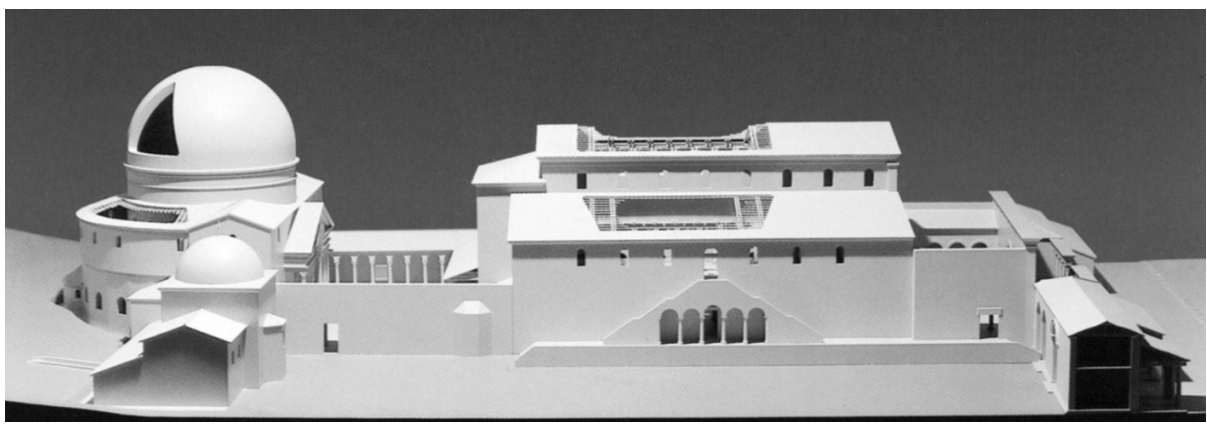

Abb. 14 Modell des spätantiken Grabeskirchen-Komplexes - hier einschließlich des Baptisteriums - von Süden im Jerusalemer Tower of David Museum (Gibson - Allen). (Biddle, Tomb [s. Anm. 2] Abb. 62)

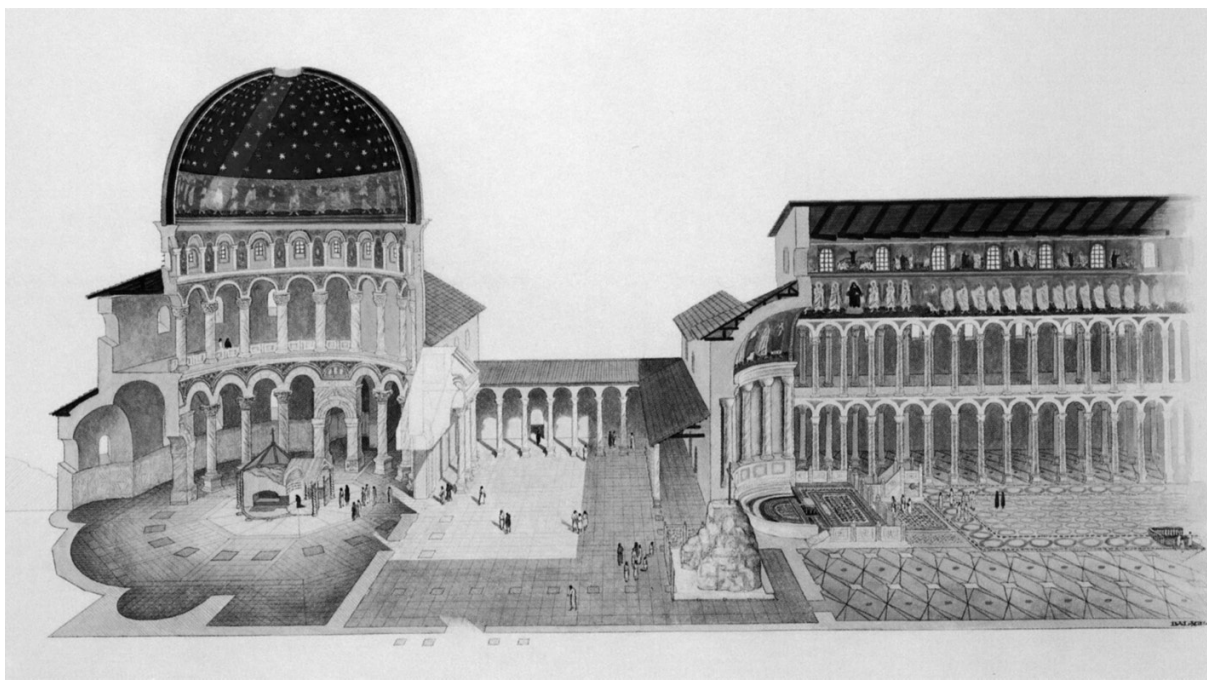

Abb. 15 Zeichnerischer Rekonstruktionsversuch von Anastasis, Zwischen-Atrium und Basilika. (Cradle of Christianity, Ausstellungskatalog Jerusalem 2000, 38)

wird. Auch dass die Kuppelrotunde eine Empore besessen hätte (Abb. 15, 19), ist nicht zu erwarten, und was die Bildausstattung anbelangt, so muss man sich die auf einer der neuesten zeichnerischen Visionen kurzerhand eingefügten, dem 5. und frühen 6. Jh. entstammenden Ravenna-Mosaiken (Abb. 15) natürlich drakonisch wegdenken. ${ }^{23}$

23 Die besagte Zeichnung gibt anderseits auch das prächtige Gemmenkreuz auf dem Golgatha-Felsen wieder, welches 422 durch Theodosius II. anstelle eines mutmaßlich schlichteren Exemplars aufgerichtet wurde, als bei der Deutung des Kreuzes gegen- 
Die Anastasis-Rotunde bewahrt bis in die Gegenwart weithin den alten Grundriss und, trotz aller Zerstörungen und Änderungen, Teile der frühchristlichen Bausubstanz, in der äußeren Mauerschale, die übrigens kaum merklich polygonal ausfällt, immerhin bis zu großer Höhe. Der innere Zylinder (Abb. 16) lässt noch die originale Stützenkonstellation - im Achsenkreuz vier Pfeilerpaare, dazwischen eingespannt jeweils drei Säulen - anklingen und bewahrt alte Substanz wenigstens in einigen der Pfeiler sowie in den Säulen, bei letzteren aber lediglich in völlig modifizierter Form, denn sie sind viel zu kurz. ${ }^{24}$ Der Umgang der Westhälfte hatte drei große, auf das Grab ausgerichtete Konchen, während es nach Osten zwei Übergangsräume gab, die über mehrere Türen zum ZwischenAtrium hin vermittelten. Auf die entscheidende Vorarbeit von Charles Coüasnon gestützt, hat Jürgen Krüger eine Schnittzeichnung der ursprünglichen Rotunde (Abb. 17) versucht. ${ }^{25}$ Zur Rekonstruktion des originalen Aufrisses gehören Postamente, Basen, Schäfte, Kapitelle und Gebälk mit einer Gesamthöhe von etwa $11 \mathrm{~m}$, darüber und über dem Dach des Umganges ein beträchtlich aufwachsender Tambour mit Fenstern und schließlich als Überdeckung die nur aus Holz denkbare Kuppel.

Mittendarin erhob sich als zweiter und gegenüber dem Golgatha-Felsen noch wichtigerer Höhepunkt und Daseinsgrund der Rotunde das Grab des Heilands, jenes einstige Felsgrab, aus dem heraus Christus nach allgemeiner Glaubensüberzeugung am dritten Tage auferstanden war. Die entscheidende Eigenschaft dieses Hohlraumes war wohlgemerkt seine Leere, d. h. hier musste gewissermaßen und nicht ohne einen Anflug des Paradoxen etwas nicht mehr Vorhandenes oder jedenfalls dessen allein noch vorhandenes Behältnis in Szene gesetzt werden. Vor einem Jahrzehnt hat Martin Biddle diesem Heiligtum eine reich illustrierte

über dem Moment von Leid und Schmach längst der Gedanke des Sieges in den Vordergrund getreten war.

24 Der Stützenkreis gehört in der Gegenwart zu einem zweistöckigen inneren, licht $21 \mathrm{~m}$ durchmessenden Zylinder, über dem die verkleidete Eisenkonstruktion der neuzeitlichen Kuppel von 1868 ansetzt. Das Ganze wirkt durchaus hochstrebend, aber für uns Heutige eben doch unbefriedigend, weil die Säulen im Erdgeschoß allen guten klassischen Proportionen Hohn sprechen: Unter nachgeschaffenen Kapitellen stehen unförmig dicke Schäfte, die man sich gerne doppelt so hoch vorstellen möchte. Offenbar exisitierten ursprünglich zwölf Schäfte mit guten Proportionen bei über $7 \mathrm{~m}$ Aufmaß (jedenfalls spricht schon ein Jerusalem-Besucher des Jahres 685, der fränkische Bischof Arculf, von zwölf Säulen), doch scheint man bei der Wiederaufrichtung der Rotunde im 11. Jh. nur noch einen Teil davon verwendet haben zu können, so dass man sie schlicht halbierte. Sehr besonnen und instruktiv hat sich Coüasnon, Church (s. Anm. 2) bes. 26-32 Taf. 16-19, 25 mit diesem Problemkreis befasst.

25 Krüger, Grabeskirche (s. Anm. 2), Abb. 58 zu S. 53-57. 


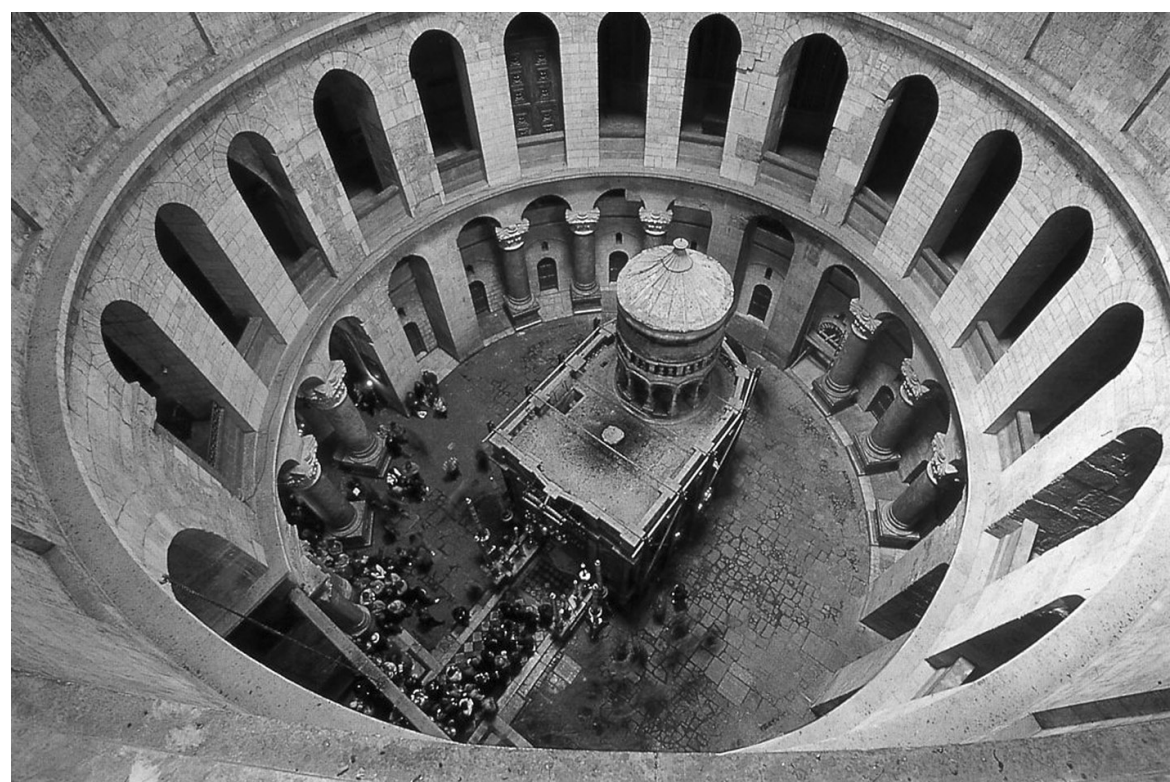

Abb. 16 Inneres der Anastasis-Rotunde im heutigen Zustand. (J. Bremer, Israel und Palästina, München 2000, 146)

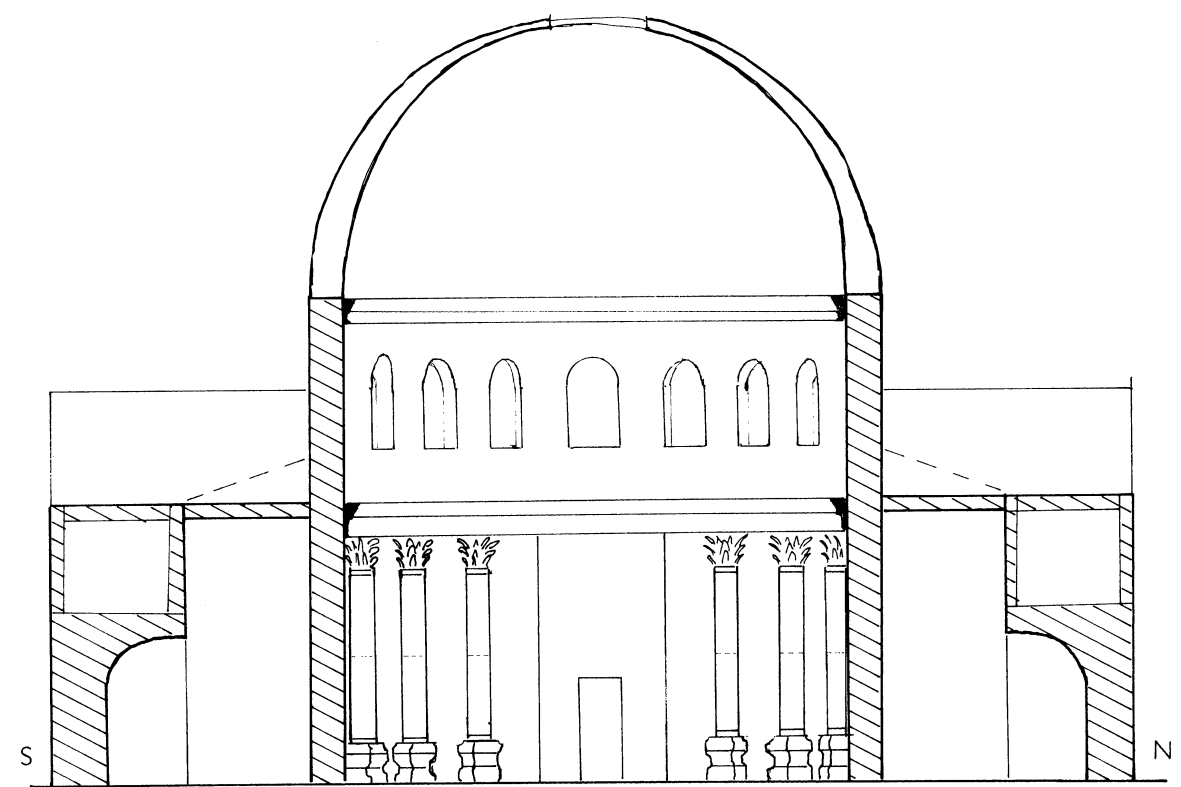

$20 \mathrm{~m}$

Abb. 17 Ideenskizze (Nord-Süd-Schnitt) zur ursprünglichen Gestalt der AnastasisRotunde. (Krüger, Grabeskirche [s. Anm. 2] Abb. 58) 

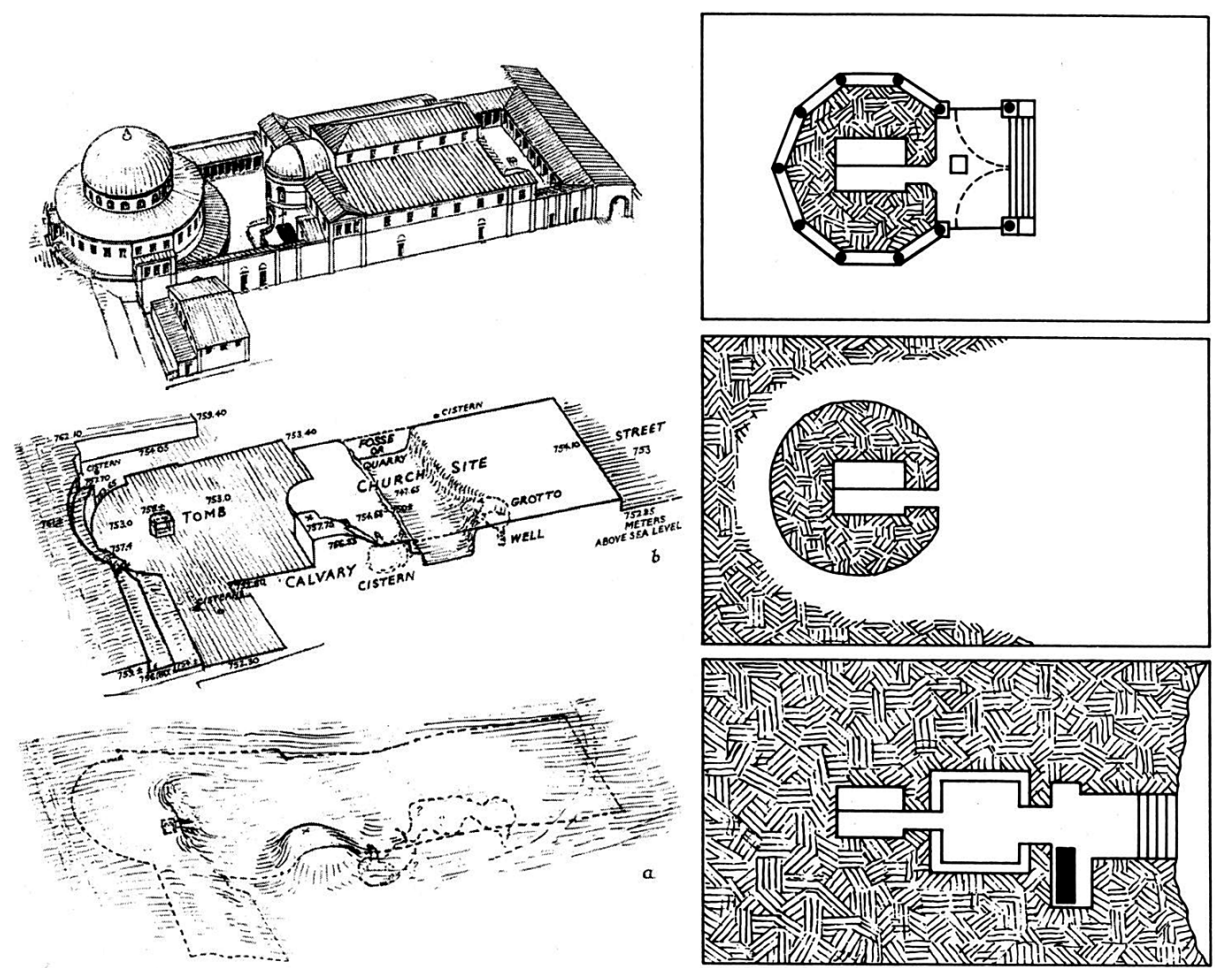

Abb. 18 Entstehungsphasen des Grabeskirchen-Komplexes (Conant) und Gestaltänderung des Herrengrabes im Laufe des 4.Jhs. (inspiriert von Wilkinson), jeweils von unten nach oben zu lesen. (Krüger, Grabeskirche [s. Anm. 2] Abb. 44 [nach Conant; reduziert] und G. Kroll, Auf den Spuren Jesu, Stuttgart 1988 Abb. 309 [reduziert])

Monographie gewidmet. ${ }^{26}$ Ursprünglich müssen wir uns die Beisetzungsstätte als ein ganz normales Felsgrab in der für die Region typischen Faktur mit einem Rollstein vorstellen, wie dieser ja auch im Evangelientext ausdrücklich überliefert wird - ein sepulcrum, dessen Inneres aus einem Vorraum und der eigentlichen Bestattungskammer besteht. Die inszenatorische Herausforderung bestand nun darin, das Grab, einen Innenraum, für die Betrachtung von außen präsentabel zu machen (Abb. 18). Es musste reliquienartig als ein einzelnes Kultobjekt in der zukünftigen Rotunde wirksam und eindrucksvoll freigestellt, es musste also mit etwas definierender Felsmasse stehen gelassen werden, während man das gesamte umgebende, nach Westen zu ansteigende Felsmassiv wegzuarbeiten hatte, auch um überhaupt die Präsentationsfläche und letzten Endes die Rotunde verwirk-

26 Biddle, Tomb (s. Anm. 2). 


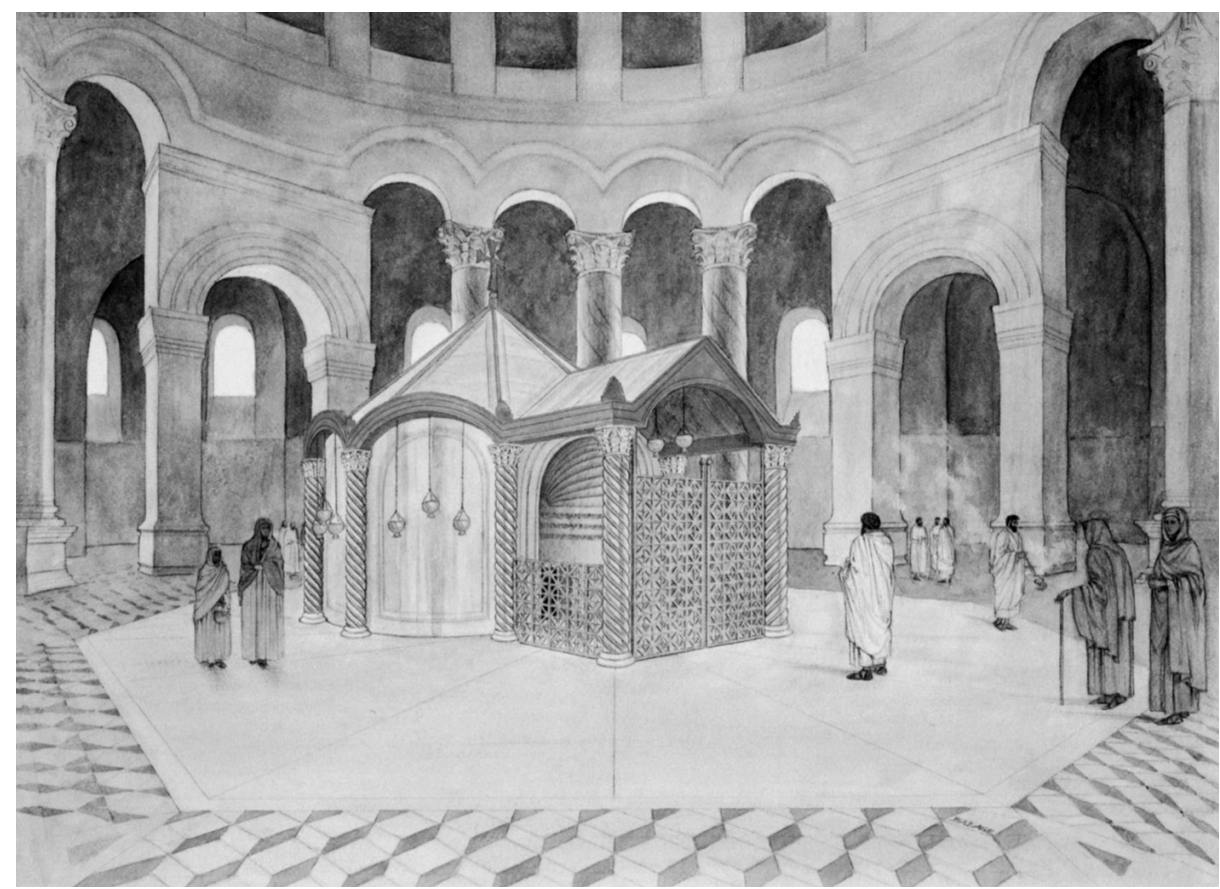

Abb. 19 Zeichnerischer Rekonstruktionsversuch der Fassung des Christusgrabes in der spätantiken Anastasis-Rotunde. Ein so freies Flanieren wie hier insinuiert war vermutlich nicht gestattet.

(Cradle of Christianity, Ausstellungskatalog Jerusalem 2000, 46)

lichen zu können. Der Bauplatz wurde nivelliert, und stehen blieb nur das Stück Fels, welches die innere Grabkammer umschloss. Dieses wurde architektonisch gefasst, wobei man den Vorraum durch einen gebauten Vorraum ersetzte. Zugänglich war das Grab selbst dann nur einem Kreis von Bevorrechtigten.

Zwar ist das Herrengrab seit der Aggression von 1009 nur mehr in tiefgreifender Brechung seiner Substanz und seines Aussehens vorhanden, doch kann man sich gegenwärtig nach Maßgabe der Reste sowie der bildlichen Reflexe und Reproduktionen doch ein wohl recht treffendes Bild von dessen spätantikem und frühmittelalterlichem Aussehen machen (Abb. 19). Zum Glück existieren nämlich einerseits etliche alte Wiedergaben des Heiligen Grabes, so u. a. auf den als ,Monza-Ampullen' geläufigen bleiernen Pilgerfläschchen (Abb. 20), wo das Grab selbst als ein kleiner einstöckiger Bau mit Schrankengittern an der Vorderseite und mit spitzem, kreuzbestücktem Dach erscheint. ${ }^{27}$ Dasselbe Sujet zeigt auch

27 D. Barag - J. Wilkinson, The Monza-Bobbio flasks and the Holy Sepulchre, in: Levant 6 (1974) 179-187; L. Kötzsche, Das Heilige Grab in Jerusalem und seine Nachfolge, in: Akten des XII. ... (s. Anm. 10), 274-276 Taf. 28a-c. 


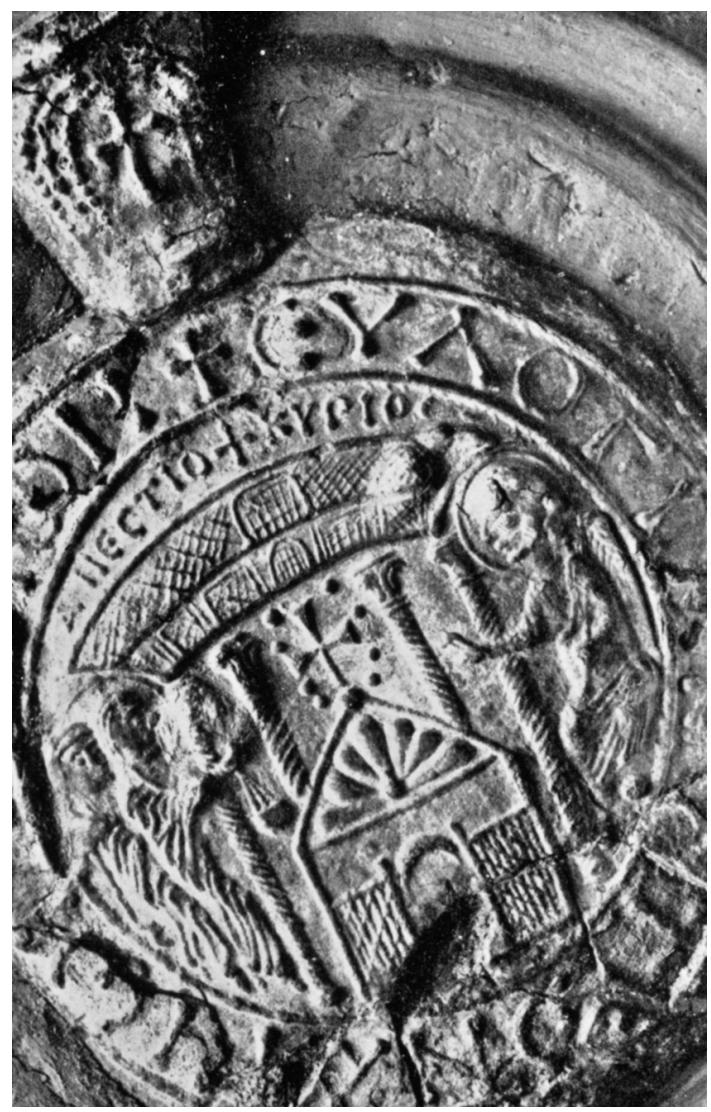

Abb. 20 Frühbyzantinische Ampulle Nr. 15 in der Sammlung des Klosters Bobbio mit Darstellung des Ostergeschehens am Grabe Christi. (A. Grabar, Ampoules de Terre Sainte, Paris 1958 Taf. 45)

ein berühmtes, der Biblioteca Apostolica Vaticana gehörendes bemaltes Kästchen für Pilgermitbringsel ${ }^{28}$ in einer Szene des bemalten Deckels (Abb. 21), und hier erkennt man nun besser, was auf den kleinen Ampullen mit ihren etwas schematisierten Darstellungen untergeht: dass es sich selbstredend um eine räumliche Struktur handelt, deren obere Partie ein veritables, zentralisierend geformtes Dach von konischer oder vieleckig-pyramidaler Form ist (bei der darüber schwebenden Hemisphäre handelt es sich natürlich um die Kuppel der Anastasis).

28 B. Reudenbach, Reliquien von Orten. Ein frühchristliches Reliquiar als Gedächtnisort, in: Reliquiare im Mittelalter, Berlin 2005, 21-41. 


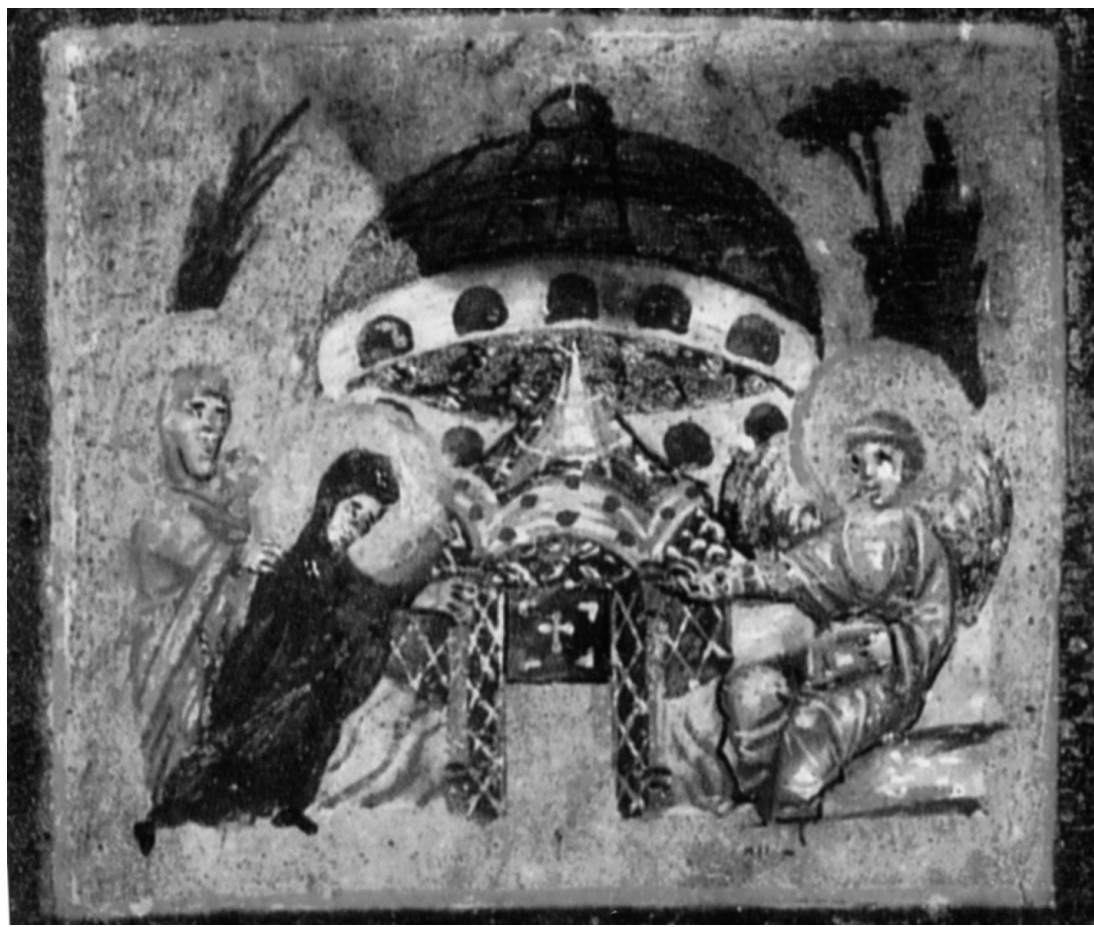

Abb. 21 Feld des bemalten Deckels am frühbyzantinischen Kästchen von Sancta Sanctorum im Museum der Biblioteca Apsotolica Vaticana mit Darstellung des Ostergeschehens am Grabe Christi. (Biddle, Tomb [s. Anm. 2] Abb. 17)

Höchst bedeutsam ist auch jenes zu unbekanntem Zweck hergestellte frühchristliche Steinmodell des Christusgrabes (Abb. 22), das man im 17. Jh. im Baumaterial der Stadtmauer von Narbonne wiedergefunden hat. ${ }^{29}$ Es zeigt eine kleine Architektur aus zentral angelegtem, säulenumstandenem Hauptraum mit konischem Dach und dem Vorraum mit Muschelwölbung und säulengestütztem Satteldach. So haben wir ein doch recht präzises, weithin anerkanntes Bild von der frühchristlichen Urfassung des Herrengrabes.

29 A. Bonnery, L'édicule du Saint-Sépulcre de Narbonne. Recherches sur l'iconographie de l'Anastasis, in: Les Cabiers de Saint-Michel de Cuxa 22 (1991) 7-42; Kötzsche, Grab (s. Anm. 27) 276-280 Taf. 29; B. Weber-Dellacroce, Marmornachbildung des Heiligen Grabes, in: Konstantin der Große (s. Anm. 16) Nr. II.2.26 (auf CD-ROM). 


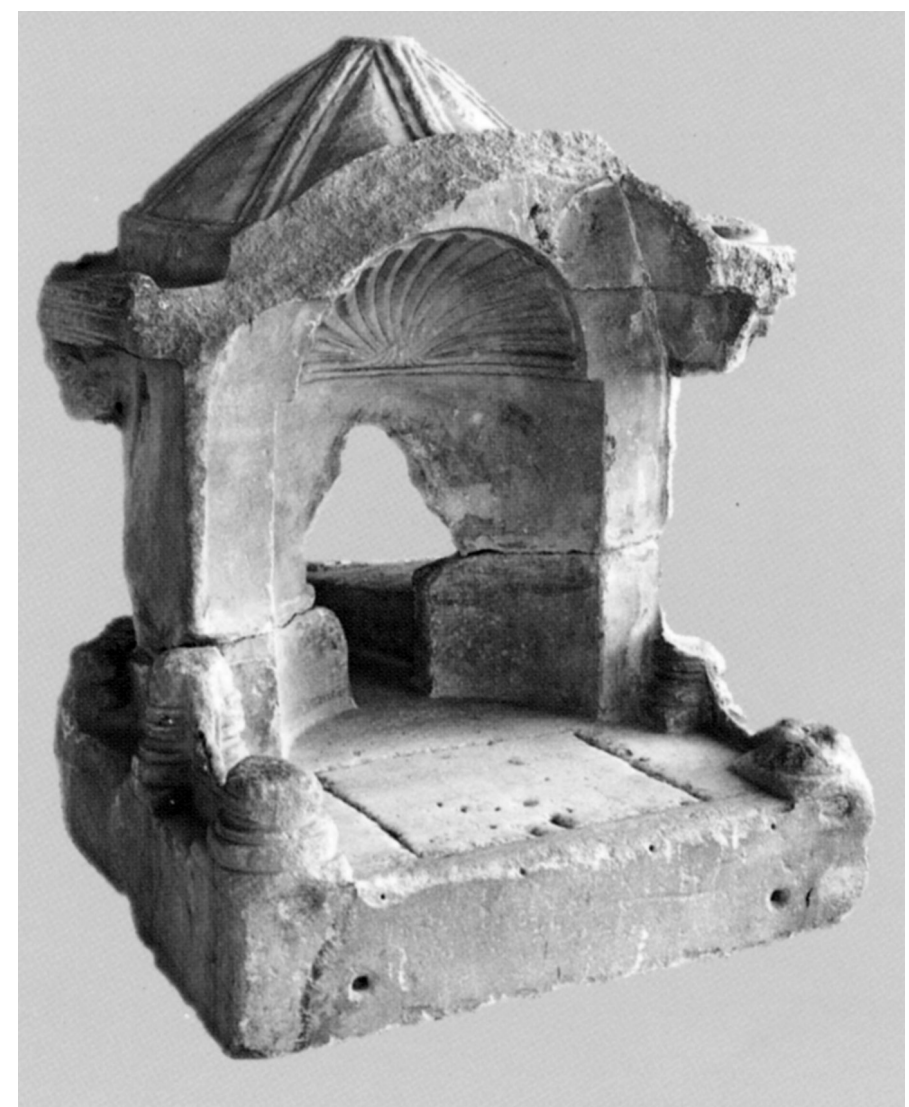

Abb. 22 Spätantikes Marmormodell (Höhe 1,24 m) des Heiligen Grabes im Musée Archéologique de Narbonne.

(Biddle, Tomb [s. Anm. 2] Abb. 16)

Mit diesen Eindrücken vom Höhepunkt des Ganzen, von der Präsentation des leeren Grabes Christi als Ziel eines Voranschreitens in allmählicher, kalkulierter inszenatorischer Steigerung sei das summarische Panorama des frühchristlichen Grabeskirchen-Komplexes abgeschlossen; welcher als das bedeutungsmäßig führende Heiligtum der Christenheit in der beschriebenen Gestalt mit nur geringen Veränderungen während der weiteren Spätantike (Abb. 23) und bis zum Anbruch des Hochmittelalters fortexistieren sollte. 


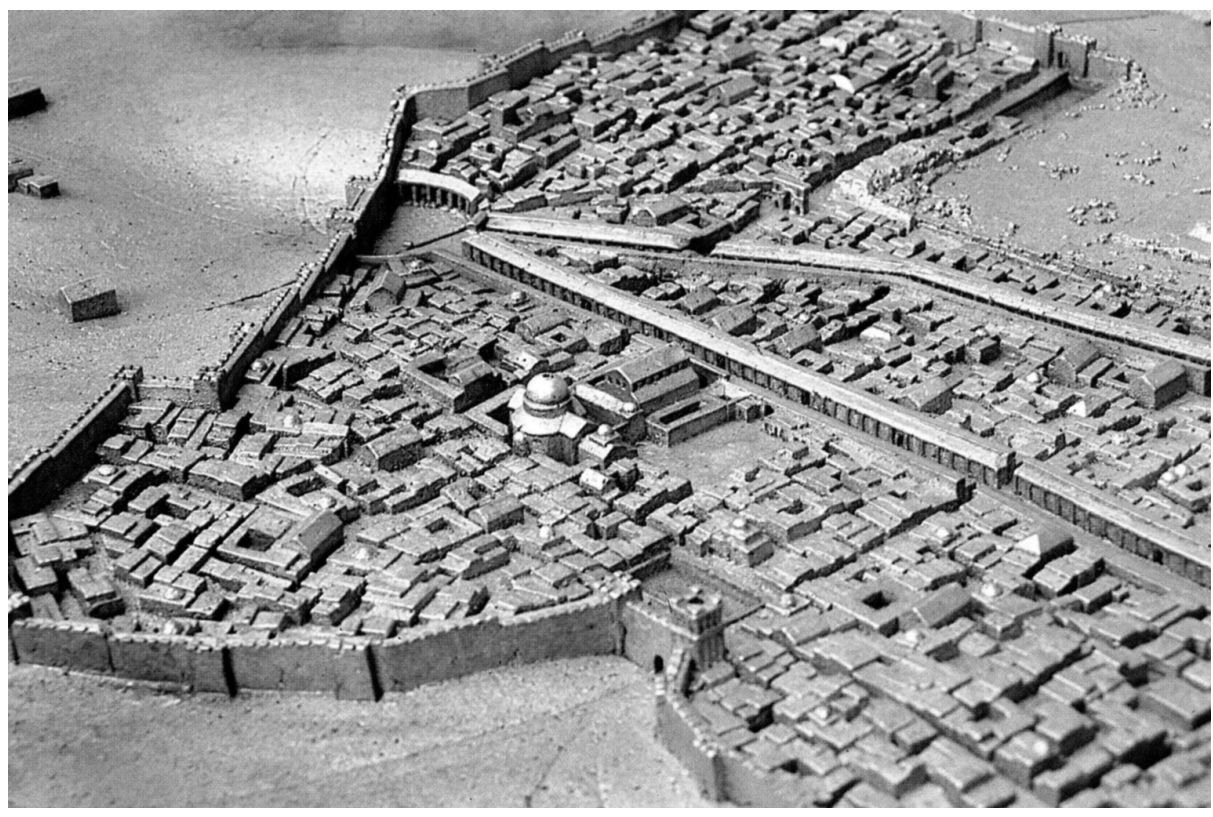

Abb. 23 Stadtmodell der frühbyzantinischen Stadt Jerusalem im Tower of David Museum. (Krüger, Grabeskirche [s. Anm. 2] Abb. 33) 
